VATT Working Papers 115

\title{
Subsidy Bidding Wars and the Structure of Multi- Plant Firms
}

Simon Lapointe

Pierre-Henri Morand 


\title{
VATT WORKING PAPERS
}

\section{5 \\ Subsidy Bidding Wars and the Structure of Multi-Plant Firms}

\author{
Simon Lapointe \\ Pierre-Henri Morand
}


Simon Lapointe, Corresponding Author, VATT Institute for Economic Research, Arkadiankatu 7, 00100 Helsinki, Finland, E-mail: simon.lapointe@vatt.fi

Pierre-Henri Morand, Avignon University, France, LBNC and AMSE

This paper was previously circulated under the title "The Impact of Subsidy Bidding Wars on the Optimal Investment Decisions of Multi-Establishment Firms.” The authors would like to thank Philippe De Donder, Nicolas Gravel, Thierry Madiès, Sonia Paty, and Tanguy van Yppersele for helpful comments and suggestions. The authors also thank participants at seminars at BETA Nancy and the University of Ottawa, as well as at the following conferences: CEA (Montreal, 2018), IIPF (Tokyo, 2017), EEA (Lisbon, 2017), AFSE (Nice, 2017), APET (Luxembourg, 2015), PEARL (Fribourg, 2013).

ISBN 978-952-274-232-2 (PDF)

ISSN 1798-0291 (PDF)

Valtion taloudellinen tutkimuskeskus

VATT Institute for Economic Research

Arkadiankatu 7, 00100 Helsinki, Finland

Helsinki, January 2019 


\title{
Subsidy Bidding Wars and the Structure of Multi-Plant Firms
}

\author{
VATT Institute for Economic Research \\ VATT Working Papers 115/2019
}

Simon Lapointe - Pierre-Henri Morand

\begin{abstract}
Governments spend large amounts of money to attract firms to their territory, often resulting from bidding wars against other regions. Previous papers show that such bidding wars can improve social welfare by allocating the investment to the regions that value it the most. In this paper, we depart from the usual assumption of exogenous, single-plant investment. We show that in this context, bidding wars incite the firm to allocate its investment strategically, by investing more and differentiating the plants. In turn, the firm receives larger subsidies. Despite these distortions, bidding wars may remain socially optimal, as in simpler models.
\end{abstract}

Key words: subsidies, regional governments, bidding wars, multi-establishment firms, auctions

JEL classes: D44, H71, H25, D21, L23 


\section{Introduction}

In 2014, Tesla chose Nevada as the location of its "gigafactory" to produce batteries for its electric cars, after that state won a bidding war by offering $\$ 1.3$ billion in subsidies and incentives. More recently, Amazon selected two sites in the United States for new headquarters through a similar bidding war, receiving more than $\$ 1$ billion in total subsidies. While these may be extreme examples, tax incentives such as these represent an appreciable amount of government spending each year and often result from bidding wars between local governments. In the United States alone, state and local governments award approximately $\$ 80$ billion in tax incentives each year to companies. ${ }^{1}$

Some see these bidding wars as wasteful, but they can play an important role in eliciting private information and improving allocation efficiency (Menezes, 2003; Fumagalli, 2003). They can also mitigate inefficiencies due to regional spillover effects (Davies, 2005), or reduce the costs of imports for losing countries (Barros and Cabral, 2000). In fact, despite paying subsidies to the firm, the winning region may actually benefit from the presence of the new plant. Greenstone and Moretti (2003), for example, compare the outcomes for winning and losing counties in contests for "million dollar plants", and find that winning counties experience greater increases in land value as well as in the total wage bill of other firms in the industry of the new plant. Greenstone et al. (2010), using the same natural experiment, find that local incumbent firms experience greater productivity increases in winning counties. While other authors also document potential positive effects of plant openings (e.g., Figlio and Bloningen, 2000), some suggest that benefits have a limited impact (Wheeler and Mody, 1992; Fox and Murray, 2004; Edmiston, 2004; Adams, 2016) or that they offset each other (Head et al., 1999). These conflicted results illustrate the need for further research. ${ }^{2}$

The examples of Tesla and Amazon highlight an important characteristic of firms involved in location contests. Soon after establishing the factory in Nevada, Tesla announced other battery plants for which it also received additional subsidies (in New York), or for which it is currently holding a location contest (in Europe). Similarly, Amazon selected two winning bids in their bidding war. In fact, the firms running bidding wars are frequently multi-establishment companies. Other examples include Boeing, which received at least $\$ 327$ million in incentives from 11 US states for multiple plants between 2007 and 2012, and Procter \& Gamble, which received at least $\$ 128$ million from 10 states over the same period. ${ }^{3}$ In other words, firms make multiple investments in short periods of time, such that the bidding wars for these plants might interact with each other.

In this paper, we explicitly account for the multi-plant nature of firms, and study how it affects both the bidding war outcomes and the organisation of the firm itself. In particular, we relax two of the assumptions made in previous literature. In our analysis, the investment

\footnotetext{
${ }^{1}$ The New York Times, "As Companies Seek Tax Deals, Governments Pay High Price," available at the following address: http://www.nytimes.com/2012/12/02/us/how-local-taxpayers-bankroll-corporations . html.

${ }^{2}$ In a 2015 poll highlighting the level of disagreement on the issue, the IGM Economic Expert Panel found that about half of the economists surveyed were uncertain whether local tax incentives were beneficial for the winning region (see http://www.igmchicago.org/surveys/local-tax-incentives).

${ }^{3}$ Other examples are available from the New York Times, at the following URL: http://www.nytimes.com/ interactive/2012/12/01/us/government-incentives.html.
} 
amount is endogenous, and it can be split across multiple sites. We show that removing these restrictions has important implications. If the firm can choose a level of capital to invest, she does so strategically. In turn, this strategic behaviour has two main effects. First, it increases the amount of capital invested. Second, the firm chooses an allocation across sites that is different from the pure profit-maximising allocation, thus affecting the organisation of the firm itself. In terms of social welfare, we find that a multi-establishment bidding war retains much of its social desirability. Indeed, the plants are allocated to the regions who value them the most. However, we derive conditions under which bidding wars may be less socially beneficial.

Specifically, we find these conclusions by adapting formal models from auction theory and mechanism design. While these bidding wars are not formal auctions, they share some characteristics: many bidders (governments) place some private value on a good (investment), and a seller (the firm) does not know how to price it, thus choosing to accept bids (subsidies). In such a case, auctions can be a useful theoretical tool (Klemperer, 2004).

To allow a better understanding of our results, we start with a simple example. Take a firm that wants to build a new plant by investing an exogenous amount of capital $K$ in one of $n$ regions. Regions receive a payoff from hosting the firm that depends on some privately-known value placed on the firm by that region. The firm chooses where to invest by conducting a simple open ascending auction. Regional governments make subsidy offers to the firm, and the winning region is the one offering the highest subsidy package. Such a bidding war has interesting properties in terms of social welfare. First, the firm is able to allocate its plant to the region that values it the most (as argued in Menezes, 2003). Second, even though these subsidies are costly (through the social cost of public funds), they can be compensated by the increase in welfare coming from the location of the plant in the "correct" region. This illustrates the basic trade-off at play in a subsidy bidding war: achieving allocative efficiency at the cost of socially costly public subsidies.

However, eliciting information and obtaining subsidies is only part of the strategic behaviour of the investing firm. The level of investment and its allocation across sites may also be strategic. In our model, we relax the assumption of fixed capital found in most of the current literature in two steps. First, we allow the firm to choose an endogenous level of capital to invest. We find that running the bidding war incites the firm to invest a larger amount of capital than she would without a bidding war. In other words, the amount of capital invested is larger than the level dictated by profit-maximisation. These lower operating profits are, however, compensated by increased subsidies.

Second, we allow the firm to invest in more than one location, essentially making multiple plants available in the bidding war. We find that the firm can allocate investment across its production sites strategically, in order to increase the subsidies she receives from regional governments. The firm invests more than it would without a bidding war (as in the singleplant model), but also differentiates the plants, investing more in one than the other. That differentiation allows the firm to attract larger total subsidies. By taking into account the linkages between the bidding wars, our model captures the infra-marginal competition between the last two remaining bidding regions for the largest plant in the auction. ${ }^{4}$

\footnotetext{
${ }^{4}$ Cowie et al. (2007) previously considered infra-marginal competition in the context of an auction. They
} 
Furthermore, we show that our results are not restricted by the choice of a specific auction type. Indeed, we find that the optimal mechanism, from the firm's viewpoint, would allocate the plants to the same winners and for the same subsidies. Moreover, this optimal mechanism could be implemented by the open ascending auction we consider, under some conditions regarding reserve subsidies. In addition, we find that if the firm does not have to commit to plant sizes before the bidding war, she invests in larger plants and extracts more informational rents from the regions.

Our paper also considers the implications of the firm's strategic choice of capital on social welfare. First, we solve the mechanism design problem from the point of view of an uninformed social planner. We find that this social planner would choose to use an efficient auction and allocating the plants to the same winner, but without reserve subsidies. We also discuss how the weights to the welfare of the regions vs. that of the firm affects the social planner's decision. If the utilities of the regions do not factor in social welfare, the firm over-invests relative to the social optimum; the firm does not take into account the deadweight loss due to the social cost of public funds.

The weight placed by a social planner on the utility of regional governments might depend on the composition of regions' private benefits. If most of the utility, say, goes to politicians to ensure their re-election, the weight in the social welfare function might reasonably close to zero. However, if the benefits concern the population as a whole, we might think that the weight on the regions' utilities is larger. This conclusion is related to the analysis of Dewatripont and Seabright (2006), who argue that politicians engage in wasteful spending such as subsidies to signal their commitment to public goods, and increase their re-election chances.

The next section discusses a selection of the literature related to this paper. Section 3 presents the framework of the model, including the timing of the game. Section 4 presents the results of a benchmark model restricted to one plant, while Section 5 solves the full model and discusses its implications on the firm's investment choices and the bidding behaviour of the regional governments. Section 6 derives the optimal mechanism from the viewpoint of the firm, with and without prior commitment to investment quantities. Section 7 discusses the welfare implications of our model, while the last section concludes.

\section{Previous Literature on Subsidy Bidding Wars}

This paper contributes to the literature on fiscal competition, and, more particularly, to the subset of papers that consider competition for a single large firm. This is in contrast to the larger stream of literature that considers the competition between regions or countries to attract units of homogeneous and perfectly divisible capital (see, e.g., Wilson, 1999).

Keen and Konrad (2014) offer a short overview of the literature considering competition for a single large firm. Early contributions include Black and Hoyt (1989), who were, to our knowledge, the first to explicitly model the firm's location choice as an auction. Before that, Doyle and van Wijnbergen (1994), in a paper first published in 1984, considered a bargaining

analyse how a seller can divide the units for sale in multiple lots in order to receive higher offers from the bidders. They find that differentiating the lots can lead to higher bids due to the infra-marginal competition for the largest lot. We have a similar reasoning in the auction stage of our model. 
game between one firm and a government over taxation. Doyle and van Wijnbergen (1994) assumed that firms negotiate with a single government at a time. Bond and Samuelson (1986) instead investigate a situation in which a firm has to decide between two locations. An important feature of their model is information asymmetry. Similarly to Bond and Samuelson (1986), information asymmetry is an important of our model, although our results are derived without productivity differences between the regions.

Our model is particularly related to the analysis of Haaparanta (1996), who uses a menu auction model. This author considers two regions competing for investment from a firm, under the assumption that this investment is divisible. However, while Haaparanta (1996) considers a model under perfect information, we instead assume that the regions' private benefits from hosting the firm are private knowledge. In fact, such information asymmetry is a justification to use a mechanism similar to an auction in the first place. As the model will show formally, analysing the question under information asymmetry will reveal new insights about the bidding war and the allocation of investment. First, when establishments are asymmetric, infra-marginal competition takes place between the last two remaining bidders, increasing the subsidy on the large plant, and allowing the firm to benefit from higher total subsidies. Second, in contrast to Haaparanta (1996), who finds that the firm captures the whole rent from the regions, in our model the information asymmetry curbs the firm's ability to extract rents from the regions.

A number of papers study specific aspects of these bidding wars (Scoones and Wen, 2001; Ferrett and Wooton, 2010; Furusawa, Hori, and Wooton, 2010). Martin (1999), for example, studies two firms in the same industry who use bidding wars sequentially to decide where to locate, showing that agglomeration effects incite regions to overbid in the first auction, expecting it will increase their probability of winning in the second period. Indeed, winning the investment in the first period from the first firm increases the attractiveness of the region to other firms in the same industry. In this paper, we also find that regions offer greater subsidies for one plant. However, we consider how a single firm can entice greater subsidies by modifying her allocation of production between two plants. In addition, we do so without considering agglomeration economies.

Finally, some authors look at dynamic models of bidding wars. King and Welling (1992) and King et al. (1993) explore the consequences of allowing the firm to relocate in later periods. They consider a two-period model, in which the firm conducts an auction to decide on its location in each period. ${ }^{5}$ King et al. (1993) assume some information asymmetry, but it is the firm who does not know its productivity in each region. In this paper, we instead assume that the regions hold some private information, while productivity is the same everywhere. This modelling choice reflect the fact that not all regions value the firm's presence identically.

\footnotetext{
${ }^{5}$ In this paper, we do not consider a two-period model. The firm installs new production facilities in one period, but we do not model the interactions in the following periods. We do so deliberately, to focus instead on how the firm decides to allocate across regions in multiple establishments in a single period. If we did consider many periods, our results could be related to those of Janeba (2000), for example, who considers a firm that installs excess production capacity in multiple regions in order to avoid the problem of hold-up by the regions. Indeed, in subsequent periods, regions could increase taxes or renege on their commitment to tax breaks (i.e., subsidies). By having excess capacity, the firm could credibly threaten to decrease production, and thus employment in the region that increased taxes, to increase it in the other.
} 


\section{The Model: Multi-Establishment Subsidy Bidding Wars as Multi-Unit Auctions}

Consider a firm that plans to build new production facilities in some of $n$ regions, indexed by $i \in 1, \ldots, n$. To decide the location of these plants, the firm puts the $n$ regional governments in competition against each other. The governments submit offers of subsidies to attract the firm to their territory. In contrast to most of the previous literature, however, the firm can divide her production in multiple locations, either in symmetric or asymmetric establishments. For simplicity and tractability, we limit the model to the case of two establishments, indexed by $j \in 1,2 .{ }^{6}$ Without loss of generality, we label the largest plant by $j=1$, so that $K_{1} \geq K_{2}$.

\subsection{The Firm}

We consider a multinational firm that already produces elsewhere, and wants to increase production by installing new establishments among the $n$ regions. Once she decided where to install the new plants, the firm produces, in each establishment, according to the production function $f\left(K_{j}, L_{j}\right)$, with $K_{j}$ the capital invested in location $j$, and $L_{j}$ the labour employed in that establishment. We make the usual assumptions that the production function exhibits decreasing returns to scale in both inputs $\left(\frac{\partial f\left(K_{j}, L_{j}\right)}{\partial K_{i}}>0, \frac{\partial f\left(K_{j}, L_{j}\right)}{\partial L_{i}}>0\right.$ and $\left.\frac{\partial f^{2}\left(K_{j}, L_{j}\right)}{\partial K_{i}^{2}}<0, \frac{\partial f^{2}\left(K_{j}, L_{j}\right)}{\partial L_{i}^{2}}<0\right) .^{7}$ The firm sells the product on a global market for a price $p$, acting as a price-taker. We deliberately do not model the goods market explicitly, to instead focus on the firm's location decision and the bidding war between regions. The production costs are identical in every region $(w, r)$.

Therefore, the firm's operating profits in each establishment $j=1,2$ are equal to

$$
\pi_{j}=p f\left(K_{j}, L_{j}\right)-w L_{j}-r K_{j}
$$

In addition to the profits from production, the firm also receives subsidies from the regions (resulting from the bidding war), so that her total ex post profits are equal to:

$$
\Pi=s_{1}^{*}+s_{2}^{*}+\pi_{1}+\pi_{2}
$$

where $s_{j}^{*}$ is the equilibrium subsidy for establishment $j$.

\subsection{The Regions}

These subsidies depend on the regions' valuation of the firm's investments. In particular, if regional government $i$ wins establishment $j$, it receives a payoff equal to

$$
V_{i j}=L_{j} \cdot b_{i}-s_{i j}
$$

\footnotetext{
${ }^{6}$ As will be evident following the exposition of the model, without restrictions on the number of plants, the firm would prefer operating an infinity of equally-sized establishments. Such organisation of production is obviously impractical, thus we limit the model to a finite number of establishments. We choose to focus on 2 plants to keep the model mathematically tractable, but the main mechanisms we wish to highlight in this paper would also be present with larger numbers of establishments.

${ }^{7}$ This assumption implies, in the model, that the firm has incentives to produce in more than one establishment.
} 
where $L_{j}$ is the number of persons employed by the firm in establishment $j, b_{i}$ is the level of private benefits from hosting the firm for region $i$ 's government, and $s_{i j}$ is the subsidy (bid) offered to the firm by region $i$ when winning establishment $j$. The subsidy can be interpreted as a total "fiscal package" offered to the firm. ${ }^{8}$

A region's private benefits $b_{i}$ are private knowledge, and they capture, for example, an increase in labour taxation from workers who will be employed by the firm, as well as spillovers to domestic firms (as in, e.g., Greenstone et al., 2010), but also the affinity between the firm and the region. ${ }^{9}$ Indeed, if the industry of the firm has a bad reputation in one region, the regional government would put only a small value on the firm's investment (due to, for example, re-election concerns). ${ }^{10}$ The private benefits are identically and independently distributed according to a distribution $g(\cdot)$ on some interval $[\underline{b}, \bar{b}]$ (with $\underline{b} \geq 0$ ). This distribution is common knowledge.

The assumptions on the distribution function imply that regions are symmetrical. They all have the same base level of publicly-known benefits $(\underline{b})$, and a certain amount of private benefits $\left(b_{i}\right)$ that follow the same distribution. Instead, we could introduce some degree of asymmetry between the regions, for example by allowing different distributions $g_{i}(\cdot)$ or different base levels $\underline{b}_{i}$. With these assumptions, we could model the bidding war as an auction with favouristism, for example. However, such considerations are outside the scope of our paper. Martin (2000) offers a model of bidding wars using such auctions.

\subsection{The Auction Process}

The equilibrium subsidies are then determined by an auction in which the firm takes the role of the auctioneer, and the regional governments submit their bids to host the firm's plants. Since there are two establishments available, the firm conducts a multi-unit auction, with both establishments available simultaneously.

The formal mechanism is an open ascending auction. More specifically, the firm runs an ascending clock, representing the current price for the lowest-value establishment still available (the one with the lowest investment). Regional governments still in the running are ready to offer a bid equal to the current price. The winning bid is determined from the price on the clock when the previous bidder withdrew from the auction. In particular, if the two establishments are still available, then when there are only two regions left bidding, the price for the lowestvalued establishment will be determined from the clock price at which the third-to-last region withdrew from the auction. ${ }^{11}$ These two remaining regions will then continue bidding until one of them exits. The clock price at which the second-to-last region withdrew will be the price for the highest-valued establishment.

\footnotetext{
${ }^{8}$ In effect, our model assumes that all regional governments have the same basic tax rate, but differentiate themselves with targeted tax holidays that may differ. This assumption may not be unreasonable in the case of sub-national jurisdictions. Even when considering countries, we are mostly interested in the competition taking place in subsidies, and abstracting from tax competition allows us to focus on our variables of interest.

${ }^{9}$ Ferrett and Wooton (2013) use a similar justification for private benefits, while Martin (2000:6) provides a more thorough list of potential explanation for these benefits.

${ }^{10}$ More generally, Buts, Jegers, and Jottier (2012) find that subsidies to firms increase support for incumbent politicians.

${ }^{11}$ Note that regions who withdraw from the auction without winning one establishment do not pay anything.
} 


\subsection{Timing}

We can summarize the timing of the whole game as follows.

Stage 0: Nature picks the set of $\left\{b_{i}\right\}_{i=1, \ldots, n}$. Regional governments learn their $b_{i}$.

Stage 1: The firm chooses and commits to an allocation of capital $\left(K_{1}, K_{2}\right)$, anticipating the subsidies offered by governments resulting from the auction in Stage 2, and the firm's own profit maximization in the last stage.

Stage 2: The multi-unit auction takes place. Winning regions offer $s_{1}^{*}$ and $s_{2}^{*}$, based on their expectation of the labour that will be employed by the firm (from profit maximzation in the last stage).

Stage 3: The firm invests capital $K_{1}$ and $K_{2}$, as determined in Stage 1, in the winning regions. She then maximizes her profits, taking capital fixed, choosing $L_{1}$ and $L_{2}$.

In the first stage, the firm commits to a certain allocation of capital. One could reasonably argue that the firm has incentives to deviate from that allocation once she receives the subsidies from the region. However, in that case, regions would anticipate these deviations and bid accordingly. To facilitate the analysis, we make the assumption that the firm can credibly commit to her allocation.

\section{Endogenous Investment in a Single-Plant Bidding War}

Before solving the full model with both endogenous investment and multiple locations, we start with a simpler version of the model. In this section, we investigate the endogenous investment decision of the firm when the decision is restricted to one plant. To that end, we restrict the model described above to only one new establishment. The set-up of the model is identical, except that the firm only chooses $K_{1}=K_{s}$.

In this restricted model, the solution in Stage 3 is simple. The firm maximizes profits in her plant by choosing $L$, with a fixed $K$ since it is chosen in Stage 1. Her maximization problem in the plant is as follows:

$$
\max _{L} p f\left(K^{*}, L\right)-w L-r K^{*}
$$

The first-order condition is $p f^{\prime}\left(K^{*}, L\right)-w=0$. This condition is standard, and defines the function $L(K)$, determining the optimal amount of labour employed for each possible equilibrium level of capital invested in the first stage.

At the auction stage, the equilibrium winning bid will be

$$
s^{*}(K)=L\left(K_{s}\right) \cdot b_{(2)}
$$

where $b_{(2)}$ is the second-highest private benefits among the $n$ competing regions (i.e., the secondorder statistic).

In the first stage, then, the firm's optimization problem is the following:

$$
\max _{K} \Pi=E\left(\pi(K)+s^{*}\right)=E\left[p f(K, L(K))-w L(K)-r K+L(K) \cdot b_{(2)}\right]
$$


where $\pi$ and $s^{*}$ are, respectively, the operating profits of the firm's plant and the equilibrium subsidy. The result of that problem leads to the following proposition.

Proposition 1. A single bidding war for a new plant of endogenous size increases the firm's investment compared to a situation without a bidding war.

Proof. The first-order condition is:

$$
\begin{aligned}
& \frac{\partial E(\Pi)}{\partial K}=L^{\prime}(K) E\left(b_{(2)}\right)+p\left(\frac{\partial f(K, L(K))}{\partial K}+\frac{\partial f(K, L(K))}{\partial L(K)} \cdot L^{\prime}(K)\right)-w L^{\prime}(K)-r=0 \\
& \frac{\partial E(\Pi)}{\partial K}=L^{\prime}(K) E\left(b_{(2)}\right)+p \frac{\partial f(K, L(K))}{\partial K}-w L^{\prime}(K)-r=0
\end{aligned}
$$

It simplifies to

$$
p \frac{\partial f(K, L(K))}{\partial K}=r+L^{\prime}(K)\left(w-E\left(b_{(2)}\right)\right)
$$

This first-order condition implies that when using a bidding war, the firm chooses to invest an amount of capital $K_{s}$ greater than would be invested without a bidding war. Indeed, the subsidies received effectively reduce the implicit cost for the firm's labour $\left(w-E\left(b_{(2)}\right)<w\right)$.

Proposition 1 shows that a single bidding war with endogenous capital already distorts the firm's investment decision, by increasing capital invested compared to a situation without a bidding war. In fact, the firm sacrifices some operating profits, but gains a larger amount in term of subsidies.

\section{Endogenous Investment in Bidding Wars for Multiple Loca- tions}

This section investigates the complete model as described in Section 2, which includes multiple simultaneous bidding wars. We solve it by backwards induction.

\subsection{Stage 3: Production}

In the last stage of the game, we find the firm's optimal labour input demand in each firm for each level of capital invested. At this stage of the game, the firm already committed to investment quantities $\left(K_{1}, K_{2}\right)$, and knows the identity of the winning regions and the amount of the subsidies. Therefore, the firm chooses $\left(L_{1}, L_{2}\right)$ to maximise her operating profits. Since the amounts of capital are fixed in each location, she solves two maximization problem, one in each plant, as follows.

$$
\max _{L_{j}} \quad p f\left(K_{j}^{*}, L_{j}\right)-w L_{j}-r K_{j}^{*}
$$

The first-order condition is

$$
p f^{\prime}\left(K_{j}^{*}, L_{j}\right)-w=0
$$

implying that the firm chooses $L_{j}$ to equalize the marginal product of that input, $f^{\prime}\left(K_{j}^{*}, L_{j}\right)$, with the ratio of $w$ and $p$. Therefore, the optimal $L_{j}$ will depend on the amount of capital 
invested, $K_{j}^{*}$. We define the function $L\left(K_{j}\right)$, determining the amount of labour employed for each possible equilibrium level of capital invested in the first stage.

Since the regions' valuation depends on the amount of labour employed, we want to know how $L$ varies with $K$. By totally differentiating the first-order condition (eq. 6), we can obtain the sign of $\frac{d L}{d K}$ :

$$
\frac{d L}{d K}=-\frac{\frac{\partial^{2} f\left(K^{*}, L^{*}\right)}{\partial K^{2}}}{\frac{\partial^{2} f\left(K^{*}, L^{*}\right)}{\partial K \partial L}}>0
$$

This derivative is greater than zero as long as the cross partial derivatives in $K$ and $L$ are positive (e.g., increasing capital increases the marginal product of labour). Therefore, a greater investment by the firm in an establishment translates into a greater valuation of that establishment by the regions.

As an example, take a simple Cobb-Douglas production function $f(K, L)=K^{\alpha} L^{\beta}$ with $\alpha+\beta<1$. In that case, for each level of $K$, she chooses an optimal amount of labour $L$ equal to

$$
L(K)=\left(\frac{p \beta}{w}\right)^{\frac{1}{1-\beta}} K^{\alpha /(1-\beta)}
$$

In this example, larger investments by the firm translate in more labour employed $\left(L^{\prime}(K)>0\right)$, but at a decreasing rate $\left(L^{\prime \prime}(K)<0\right)$.

\subsection{Stage 2: Auction and Equilibrium Subsidies}

In the auction stage, the firm puts up two plants for sale of sizes $K_{1}$ and $K_{2}$. The regional governments expect the firm to employ $L\left(K_{1}\right)$ and $L\left(K_{2}\right)$, respectively, and bid according to their valuation functions $V_{i j}$. More specifically, regions decide when to withdraw from the auction (i.e., a stopping price), in which the current price is indicated on an ascending clock. The following lemma describes the equilibrium subsidies resulting from the auction.

Lemma 1. The equilibrium bids for the two establishments will be equal to

$$
\begin{aligned}
& s_{1}^{*}\left(K_{1}, K_{2}\right)=\left(L^{*}\left(K_{1}\right)-L^{*}\left(K_{2}\right)\right) b_{(2)}+L^{*}\left(K_{2}\right) b_{(3)} \\
& s_{2}^{*}\left(K_{1}, K_{2}\right)=L^{*}\left(K_{2}\right) \cdot b_{(3)}
\end{aligned}
$$

where $b_{(z)}$ is the $z^{\text {th }}$-highest signal among the $n$ regions.

Proof. See Appendix.

First note that, as expected, if $K_{1}=K_{2}$, then $s_{1}^{*}\left(K_{1}, K_{2}\right)=s_{2}^{*}\left(K_{1}, K_{2}\right)$. In the more interesting case of asymmetric establishments, the value of $s_{1}^{*}\left(K_{1}, K_{2}\right)$ is determined through infra-marginal competition between the last two remaining bidders. At that stage of the auction, both regional governments still standing are guaranteed to win one of the establishments. Therefore, the decision is based on a comparison of the payoffs from winning each plant, and paying the corresponding subsidy (i.e., $L\left(K_{1}\right) b_{(2)}-s_{1}^{*}\left(K_{1}, K_{2}\right)=L\left(K_{2}\right) b_{(2)}-s_{2}^{*}\left(K_{1}, K_{2}\right)$ ). Notably, increasing $K_{2}$ has an ambiguous effect on the total subsidies received by the firm. On the one hand, it increases the value of the smaller plant, so the corresponding subsidy increases 
$\left(\frac{\partial s_{2}}{\partial K_{2}}=b_{(3)}>0\right)$. On the other hand, it increases the opportunity cost to the winner of the large plant, thus reducing the subsidy for the largest plant $\left(\frac{\partial s_{1}}{\partial K_{2}}=b_{(3)}-b_{(2)}<0\right)$.

\subsection{Stage 1: The Firm's Optimal Location Choice}

In the first stage, the firm's optimisation problem is the following:

$$
\max _{K_{1}, K_{2}} E\left(s_{1}^{*}+s_{2}^{*}+\pi_{1}+\pi_{2}\right)
$$

where $\pi_{j}=p f\left(K_{j}, L_{j}\right)-w L_{j}-r K_{j}$ and $s_{j}^{*}$ are, respectively, the operating profits in each establishment and the equilibrium subsidies as determined in Lemma 2.1. The firm thus chooses $K_{1}$ and $K_{2}$ to maximise her total expected profits, anticipating the bids of the regions, as well as her profit maximisation in the last stage. The solution to this optimisation problem leads to the following proposition.

Proposition 2. When the firm allocates her production units through a multi-unit auction, she always chooses to differentiate the two establishments $\left(K_{1} \neq K_{2}\right)$.

Proof. See Appendix.

This proposition thus states that the firm will always choose to have differentiated production units. To better understand the the trade-offs at play, we can rearrange the first-order conditions from the optimisation problem in eq. (10) as such:

$$
\begin{aligned}
& p \frac{\partial f\left(K_{1}, L\left(K_{1}\right)\right)}{\partial K_{1}}=L^{\prime}\left(K_{1}\right)\left(w-E\left(b_{(2)}\right)\right)+r \\
& p \frac{\partial f\left(K_{2}, L\left(K_{2}\right)\right)}{\partial K_{2}}=L^{\prime}\left(K_{2}\right)\left(w+E\left(b_{(2)}\right)-2 E\left(b_{(3)}\right)\right)+r
\end{aligned}
$$

In each establishment, the firm's choice of $K_{j}$ reflects the usual trade-off of marginal revenues and marginal costs. However, the marginal cost of labour is not simply equal to the wages paid. In fact, the firm receives subsidies that depend on the level of employment, effectively lowering the firm's marginal labour costs. Therefore, when the firm increases $K_{j}$, her labour costs increase not simply by $L^{\prime}\left(K_{j}\right) \cdot w$, but by an amount with wages "adjusted" by the marginal subsidies. Since these adjustments are unequal, the optimal investment amounts will also be unequal in the two plants.

Denoting total equilibrium subsidies by $s_{t}^{*}$, we find that $\frac{\partial s_{t}^{*}}{\partial K_{1}}=E\left(b_{(2)}\right)$ and $\frac{\partial s_{t}^{*}}{\partial K_{2}}=-E\left(b_{(2)}\right)+$ $2 E\left(b_{(3)}\right)$. An increase in $K_{1}$ has an unambiguous effect: it increases subsidies for the largest plant, and thus reduces the "adjusted" marginal cost for that plant. An increase in $K_{2}$, however, could increase or decrease the "adjusted" marginal cost for the smaller plant, for the reasons outlined in the discussion on subsidies. Indeed, while increasing $K_{2}$ increases the value of the small plant, and thus the corresponding subsidy, it also increases the foregone value for the winner of the largest plant.

Having solved all the stages of the game, we can describe the sub-game perfect Nash equilibrium. In it, the firm commits in Stage 1 to $\left(K_{1}^{*}, K_{2}^{*}\right)$, defined by the first-order conditions (11) and (12). In Stage 2, the regions bid until the price on the clock passes their valuation. The 
region with the highest private benefits wins the largest establishment and offers subsidies of $s_{1}^{*}\left(K_{1}, K_{2}\right)=\left(L^{*}\left(K_{1}\right)-L^{*}\left(K_{2}\right)\right) b_{(2)}+L^{*}\left(K_{2}\right) b_{(3)}$. The region with the second-highest private benefits wins the smaller establishment, paying subsidies equal to $s_{2}^{*}\left(K_{1}, K_{2}\right)=L^{*}\left(K_{2}\right) \cdot b_{(3)}$. In Stage 3, the firm invests the amounts $\left(K_{1}^{*}, K_{2}^{*}\right)$, employs labour $L\left(K_{j}\right)$ in each establishment $j$, and produces according to $f(\cdot)$.

\subsection{Equilibrium Amount of Investment: Bidding War vs. No Bidding War}

For comparison purposes, without a bidding war, the firm would choose to invest an equal amount of capital in two random regions. Indeed, the firm's revenues are then simply equal to $\pi_{1}\left(K_{1}\right)+\pi_{2}\left(K_{2}\right)$. The first-order conditions are

$$
\begin{aligned}
& p \cdot \frac{\partial f\left(K_{1}, L\left(K_{1}\right)\right)}{\partial K_{1}}=w L^{\prime}\left(K_{1}\right)+r \\
& p \cdot \frac{\partial f\left(K_{2}, L\left(K_{2}\right)\right)}{\partial K_{2}}=w L^{\prime}\left(K_{2}\right)+r
\end{aligned}
$$

Put differently, the firm's optimal allocation in this case simply results from equating marginal revenues and marginal costs in each establishment. The assumptions on the production function imply that the firm chooses an identical investment in both plants: $K_{n b w}$.

Since the firm has no information about the private benefits of the regions, and since regions are identical in terms of productive capacity, the firm chooses to invest an equal amount $K_{n b w}$ in two regions. She can just choose two regions at random, since her production costs and profits will be identical with any set of two regions.

This comparison begs the question whether the firm invests more in total when allocating through a bidding war than when she randomly chooses two regions to invest in. Intuitively, one might suspect that the firm always chooses a larger $K_{1}$ when using a bidding war. We prove this intermediary result in the following lemma.

Lemma 2. The capital investment in the first establishment $\left(K_{1}\right)$ is always greater under a bidding war than without a bidding war.

Proof. As long as $E\left(b_{(2)}\right)>0$, the adjusted wages (i.e., accounting for subsidies) are lower than $w$. Indeed, $w>w-E\left(b_{(2)}\right)$. Therefore, $K_{1}^{*}>K_{n b w}$.

The intuition is less clear in the case of the second establishment. Indeed, $E\left(b_{(2)}\right)-2 E\left(b_{(3)}\right)$ could be greater or smaller than zero, depending on the distribution of the private benefits. In turn, investment could be lower or higher than without a bidding war. With a uniform distribution, it is easy to see that $K_{2}^{*}$ will be greater than (with $n>3$ ) or equal to (with $n=3$ ) $K_{n b w}$. In the following lemma, we show that the opposite is possible.

Lemma 3. There exists some distribution of private benefits for which the firm invests less in the second establishment under a bidding war than without a bidding war.

Proof. See Appendix.

A distribution function that fits this description would be strongly skewed to the right, giving more weight to values closer to zero. In economic terms, it would translate in a situation 
where one or few regions put a great value on the firm's presence, while the majority of regions put little to no value. In such a case, the firm might be able to extract a large subsidy from one government, but the differentiation comes at the cost of lower production in, and lower subsidies for, the second plant.

We are ultimately interested in the comparison of $K_{1}^{*}+K_{2}^{*}$ and $2 \times K_{n b w}$. From Lemma 2 , we know that $K_{1}^{*}>K_{n b w}$, so for total investment to be lower under a bidding war, it is necessary that $K_{2}^{*}<K_{n b w}$ by an amount large enough to counter-balance the increase in the first establishment.

Proposition 3. Under conditions on the relative concavity of the production and labour demand functions, the total amount invested by the firm under a bidding war is always larger than the amount she would invest without a bidding war.

Proof. See Appendix.

In particular, one condition for this proposition to be true imply that the production function must "bend more" than the labour demand function. Notably, this is also a condition to obtain an interior solution to profit maximisation in the first place. However, for Proposition 3 to be true, we do need additional conditions on the third derivatives of the production and labour demand functions. However, note that the proof makes no assumption on the distribution of the regions' private benefits, other than they are always non-negative.

To illustrate the proposition, we follow Haaparanta (1996) and use a Cobb-Douglas production function. We show that in this case, the decrease in $K_{2}$ is never large enough to counter-balance the increase in $K_{1}$. In other words, total investment is always larger when using a bidding war than without a bidding war.

Corollary 1. Assuming a Cobb-Douglas production function with decreasing returns to scale $(\alpha+\beta<1)$, the total amount invested by the firm under a bidding war is always larger than the amount she would invest without a bidding war.

Proof. See Appendix.

\section{The Firm's Optimal Mechanism for the Allocation of Invest- ment}

So far, this paper considered that the firm allocated the plants using an open ascending auction. However, the firm might prefer another type of selling mechanism. This section describes the optimal mechanism of the firm and compares it to the open ascending auction. It then discusses the role of the firm's commitment to investment quantities before the auction.

\subsection{Optimal Mechanism}

Assume for now, as we did in previous sections, that the firm first chooses and commits to values of $K_{1}$ and $K_{2}$, and then chooses the selling mechanism. We have $n$ regional governments, each willing to buy up to one unit of production from a firm. Each regional government $i$ has a 
private valuation per labour unit employed in the firm's production of $b_{i}$. The $b_{i}$ are identically and independently distributed according to $g(\cdot)$ on the interval $[\underline{b}, \bar{b}]$. Define $b=\left(b_{1}, \ldots, b_{n}\right)$, $B_{i}=[\underline{b}, \bar{b}]$, and $B=\Pi_{i} B_{i}=[\underline{b}, \bar{b}]^{n}$. The firm has two units of production available, $j=1,2$. We define $x_{i}(b)=\left(x_{i, 1}(b), x_{i, 2}(b)\right)$ as the allocation function vector, with $x_{i, j}(b) \in[0,1]$, and $s_{i}\left(b_{i}, b_{-i}\right)$ as the payment from the region to the firm. Then, the expected payoff to a regional government is equal to $V_{i}=x_{i, 1}(b) L\left(K_{1}\right) b_{i}+x_{i, 2}(b) L\left(K_{2}\right) b_{i}$, and the expected utility is:

$$
E U_{i}\left(x_{i}, b, s_{i}\right)=\int_{B_{-i}}\left(x_{i, 1}\left(b_{i}, b_{-i}\right) L\left(K_{1}\right) b_{i}+x_{i, 2}\left(b_{i}, b_{-i}\right) L\left(K_{2}\right) b_{i}-s_{i}\left(b_{i}, b_{-i}\right)\right) g_{-i}\left(b_{-i}\right) d b_{-i}
$$

The firm wants to maximise

$$
E(\Pi)=\pi_{1}\left(K_{1}\right)+\pi_{2}\left(K_{2}\right)+\sum_{i=1}^{n} \int_{B} s_{i}(b) g(b) d b
$$

The firm plays a two-stage game. She chooses $\left(K_{1}, K_{2}\right)$ in a first stage, and then chooses and implements a mechanism to allocate these two plants while receiving subsidies from regional governments. In the second stage, the firm's objective is to choose a mechanism to maximise her profits.

We start by solving the second stage. Using the revelation principle, we can restrict our attention to direct mechanism characterised by a set of functions $\left\{x_{i 1}(b), x_{i 2}(b), s_{i}(b)\right\}_{i=1, \ldots n}$ where the $x_{i j}$ 's reflect the allocation rule of plant $j=1,2$ and the $s_{i}$ 's reflect the payment rule, when $b$ is the vector of types reported by the regions. We find such a mechanism using the usual tools (Myerson, 1981). Formally, after standard manipulations and defining $\beta\left(b_{i}\right)=b_{i}-\frac{1-G\left(b_{i}\right)}{g\left(b_{i}\right)}$, the problem can be stated as follows as a simplified optimisation problem (see the proof of Lemma 4 in the appendix):

$$
\begin{array}{ll}
\max _{x(b)} & \sum_{i} \int_{B} \sum_{j=1}^{2} x_{i j}(b)\left[\beta_{i}\left(b_{i}\right) L\left(K_{j}\right)+\pi_{j}\left(K_{j}\right)\right] g(b) d b \\
\text { s.t. } & E U_{i}\left(x_{i}, \underline{b}, s_{i}\right)=0 \quad \forall i \\
& \left(\tilde{b}_{i}-b_{i}\right) \sum_{i=1}^{2} p_{i j}\left(x_{i}, b_{i}\right) L\left(K_{j}\right) \geq\left(\tilde{b}_{i}-b_{i}\right) \sum_{i=1}^{2} p_{i j}\left(x_{i}, \tilde{b_{i}}\right) L\left(K_{j}\right) \quad \forall b_{i}<\tilde{b}_{i} \\
& \sum_{i=1}^{n} x_{i j} \leq 1 \quad \forall j=1,2 \\
& x_{i j}(b) \geq 0 \quad \forall i, j \\
& x_{i 1}(b)+x_{i 2}(b) \leq 1 \quad \forall i
\end{array}
$$

while the optimal payment can be written as:

$$
s_{i}^{*}(b)=b_{i}\left(x_{i 1}(b) L\left(K_{1}\right)+x_{i 2}(b) L\left(K_{2}\right)\right)-\int_{\underline{b}}^{b_{i}}\left(x_{i 1}\left(t, b_{-i}\right)+x_{i 2}\left(t, b_{-i}\right)\right) d t
$$

Lemma 4. Allocative efficiency: The optimal mechanism from the viewpoint of the firm allocates the plants to the regions that value it the most, who pay an amount equal to their valuation minus the informational rent $\beta\left(b_{i}\right)=b_{i}-\frac{1-G\left(b_{i}\right)}{g\left(b_{i}\right)}$. 
Proof. See Appendix.

Notably, this result implies that it's never optimal for the firm to allocate the plants randomly. This traditional result of optimal auction mechanism stems from our assumption of symmetric regions, which implies symmetry between informational rents. These rents are decreasing with the level of private benefits, such that under usual assumptions relative to the distribution function, we have $\beta\left(b_{i}\right)$ increasing in $b_{i}$. Therefore, the firm can not do better than allocating the largest plan to the region revealing the highest private benefit and allocating the second plant to the region with the second-highest private benefits.

How does this optimal mechanism compare to the open ascending (and efficient) auction used in our previous model? Does it implement the optimal mechanism? This is an issue that addressed the fact that, first, the optimal mechanism means not allocating both plants or the smallest one if regions reveal too small private benefits (the optimal auction may not be expost efficient) and that, second, it may, in turn, modify the optimal level $\left(K_{1}, K_{2}\right)$. Indeed, the firm can increase her expected global profit by giving up the operational profits while not allocating the plants. Consider first the largest plant. For all $b_{i} \leq \tilde{\beta}_{1}$ with $\tilde{\beta}_{1}=\beta^{-1}\left(\pi_{1}\left(K_{1}\right)\right)$, allocating the plants reduces the expected profit (as $\left.b_{i}-\frac{1-G\left(b_{i}\right)}{g\left(b_{i}\right)}+\pi_{1}\left(K_{1}\right) \leq 0 \quad \forall i=1, \ldots n\right)$.

Now, if there exists one $b_{i} \geq \tilde{\beta}_{1}$, and $\forall j \neq i \quad b_{j} \leq \tilde{\beta}_{2}$ with $\tilde{\beta}_{2}=\beta^{-1}\left(\pi_{2}\left(K_{2}\right)\right)$, allocating only the largest plant is optimal. $\tilde{\beta}_{1}$ and $\tilde{\beta}_{2}$ work as reserve prices in auction: by announcing reservation subsidies of $\tilde{\beta}_{1}$ and $\tilde{\beta}_{2}$, the firm risks a probability of not building plants even though regions are willing to pay a positive amount for the plants; but the firm also increases her expected revenue, because she can command a higher subsidies when the plants are allocated. Our first result describes cases when the firm's optimal mechanism allocates both plants (reserve prices do not bind).

Proposition 4. If $p$ is large enough, a multi-unit open ascending auction always allocating two establishments with respective investment levels $K_{1}$ and $K_{2}$ determined by (10) implements the optimal mechanism found in Lemma 4 .

Proof. We start by describing the situations in which the optimal mechanism will imply no reserve subsidies.

If the private benefits revealed through the mechanism are equal to $\underline{b}$, the lowest possible level, the payoff to the firm must respect the following condition:

$$
\pi\left(K_{j}\right)+\beta(\underline{b}) L\left(K_{j}\right)=p f\left(K_{j}, L\left(K_{j}\right)\right)-L\left(K_{j}\right)(w-\beta(\underline{b}))-r K_{j} \geq 0
$$

Notably, $K_{j}=0$ respects this condition. Moreover, given the assumptions on the production function, we know that the slopes of $p f\left(K_{j}, L\left(K_{j}\right)\right)$ and $L\left(K_{j}\right)(w-\beta(\underline{b}))+r K_{j}$ are positive. Therefore, two cases are possible at $K_{j}=\epsilon$ (i.e., an arbitrary small level of investment):

- The firm makes positive profits: $p f\left(K_{j}, L\left(K_{j}\right)\right)-L\left(K_{j}\right)(w-\beta(\underline{b}))-r K_{j}>0$

- The firm does not make profit: $p f\left(K_{j}, L\left(K_{j}\right)\right)-L\left(K_{j}\right)(w-\beta(\underline{b}))-r K_{j}<0$

In the second case, we can conclude that for any $K_{j}>\epsilon$, she never makes profits if the winning region has private benefits $\underline{b}$. In the first case, we can conclude that the firm will make positive 
profits up to a certain point $\bar{K}$ (where $p f(\bar{K}, L(\bar{K}))=L(\bar{K})(w-\beta(\underline{b}))+r \bar{K})$. Assuming that $p$ is large enough, we are always in the first situation.

Under these assumptions, the firm always makes profits at $\underline{b}$. If the private benefits revealed in the mechanism are higher, she also necessarily makes profits. Then, the optimal mechanism does not imply any reserve subsidies.

Similarly to standard problems in mechanism design, the optimal allocation function is deterministic: optimizing (15) point-wise, $x^{*}(b)$ takes value of 0 or 1 . In particular, the firm will allocate the first production unit $L\left(K_{1}\right)$ to the region with the highest virtual valuation (equivalently, to the one with highest private benefits), and the second one $L\left(K_{2}\right)$ to the region with second-highest virtual valuation. Defining $b_{(k)}$ as the $k$-th highest private benefits, we thus have

$$
x^{*}(b)=\left(x_{1}^{*}(b), x_{2}^{*}(b)\right)= \begin{cases}(1,0) & \text { if } \quad b=b_{(1)} \\ (0,1) & \text { if } \quad b=b_{(2)} \\ (0,0) & \text { otherwise }\end{cases}
$$

The optimal payment rule (16) can be rewritten taking this optimal allocation functions into account. First note that the first term in (16) is simply the value to the region of hosting the firm. For the region hosting $K_{1}$, it is equal to $b_{(1)} L\left(K_{1}\right)$, while for the region hosting $K_{2}$ it is equal to $b_{(2)} L\left(K_{2}\right)$. The second term can be interpreted as the informational rent going to the regions. Define $z_{i j}\left(b_{-i}\right)$ as the lowest value of private benefits that a region $i$ can announce and still win establishment $j$. The integral in the second term then takes the following values:

$\int_{\underline{b}}^{b_{i}} x_{i}^{*}\left(t, b_{-i}\right) L d t= \begin{cases}L\left(K_{1}\right) b_{i}-L\left(K_{1}\right) b_{(2)}+L\left(K_{2}\right) b_{(2)}-L\left(K_{2}\right) b_{(3)} & \text { if } \quad b_{i}>z_{i 1}\left(b_{-i}\right) \\ L\left(K_{2}\right) b_{i}-L\left(K_{2}\right) b_{(3)} & \text { if } \quad z_{i 1}\left(b_{-i}\right)>b_{i}>z_{i 2}\left(b_{-i}\right) \\ 0 & \text { otherwise }\end{cases}$

The first case warrants some discussion. If a region's private benefits are greater than $z_{i 1}\left(b_{-i}\right)$, such that it wins the first establishment, we also need to take into account the fact that by winning the first establishment, that region also renounces to the smaller establishment. We can see this more clearly when developing the expression to integrate: $\int_{\underline{b}}^{b_{i}} x_{i}^{*}\left(t, b_{-i}\right) L d t=$ $\int_{\underline{b}}^{b_{i}}\left(x_{i 1}^{*}\left(t, b_{-i}\right) L\left(K_{1}\right)+x_{i 2}^{*}\left(t, b_{-i}\right) L\left(K_{2}\right)\right) d t$. When calculating the integral over the interval $\left[\underline{b}, b_{i}\right]$, we have to take into account that $x(b)$ takes non-null values not only over the interval in which the region wins the first establishment, but also over the interval over which the regions wins the second establishment. These results lead to the following payments

$$
s_{i}^{*}(b)= \begin{cases}\left(L\left(K_{1}\right)-L\left(K_{2}\right)\right) b_{(2)}+L\left(K_{2}\right) b_{(3)} & \text { if } \quad b_{i}>z_{i 1}\left(b_{-i}\right) \\ L\left(K_{2}\right) b_{(3)} & \text { if } z_{i 1}\left(b_{-i}\right)>b_{i}>z_{i 2}\left(b_{-i}\right) \\ 0 & \text { otherwise }\end{cases}
$$

These are exactly the same payments found in the auction in the previous sections. Since that auction led to the same allocation and the same payments, we can conclude that the auction implemented the optimal mechanism, from the point of view of the firm. 
The optimal level of investments can be determined, rearranging (15), through the following:

$$
\max _{K_{1}, K_{2}} \int_{B}\left[\left(L\left(K_{1}\right)-L\left(K_{2}\right)\right) b_{(2)}+L\left(K_{2}\right) b_{(3)}+\pi_{1}\left(K_{1}\right)\right]+\left[L\left(K_{2}\right) b_{(3)}+\pi_{2}\left(K_{2}\right)\right] g(b) d b
$$

They correspond to (10), the optimal level of investment determined in the multi-unit auction model of the previous section.

In cases where the optimal mechanism implies reserve subsidies, the optimal investment level can differ from the one derived in the simple multi-unit auction model (eq. 10). The following corollary describes that difference.

Corollary 2. If the conditions of Proposition 4 are not respected, the optimal mechanism can be implemented by a multi-unit open ascending auction requiring a minimum level of subsidies of $\tilde{\beta}_{1}$ and $\tilde{\beta}_{2}$, with a higher level of investments but with a positive probability of non-award.

Proof. In circumstances where the optimal mechanism implies reserve subsidies, i.e.:

$$
p f\left(K_{j}, L\left(K_{j}\right)\right)-L\left(K_{j}\right)(w-\beta(\underline{b}))-r K_{j} \leq 0 \Leftrightarrow p \leq \frac{\left.L\left(K_{j}\right)\left(w-\underline{b}+\frac{1}{g(\underline{b})}\right)+r k_{j}\right)}{f\left(K_{j}, L\left(K_{j}\right)\right.}
$$

we define $\tilde{\beta}_{1}=\beta^{-1}\left(\pi_{1}\left(K_{1}\right)\right)$ and $\tilde{\beta}_{2}=\beta^{-1}\left(\pi_{2}\left(K_{2}\right)\right)$ as the minimum of subsidies required. In this case, it is optimal for the firm to risk a probability of not building the plants (and so abandon operating profits) in order to obtain on average higher subsidies.

$$
\left\{\begin{array}{l}
z_{i 1}\left(b_{-i}\right)=\max \left(\tilde{\beta}_{1}, b_{(2)}\right) \\
z_{i 2}\left(b_{-i}\right)=\max \left(\tilde{\beta}_{2}, b_{(3)}\right)
\end{array}\right.
$$

The optimal allocation rule is so modified as:

$$
x^{*}(b)=\left(x_{1}^{*}(b), x_{2}^{*}(b)\right)= \begin{cases}(1,0) & \text { if } \quad b=b_{(1)} \text { and } b \geq \tilde{\beta}_{1} \\ (0,1) & \text { if } \quad b=b_{(2)} \text { and } b \geq \tilde{\beta}_{2} \\ (0,0) & \text { otherwise }\end{cases}
$$

and the optimal payment rule as:

$$
s^{*}(b)= \begin{cases}\left(L\left(K_{1}\right)-L\left(K_{2}\right)\right) \max \left(\tilde{\beta}_{1}, b_{(2)}\right)+L\left(K_{2}\right) \max \left(\tilde{\beta}_{2}, b_{(3)}\right) & \text { if } \quad b_{i}>z_{i 1}\left(b_{-i}\right) \\ L\left(K_{2}\right)\left(\max \left(\tilde{\beta}_{2}, b_{(3)}\right)\right) & \text { if } \quad z_{i 1}\left(b_{-i}\right)>b_{i}>z_{i 2}\left(b_{-i}\right) \\ 0 & \text { otherwise }\end{cases}
$$

The optimal level of investments can be determined by the following:

$$
\begin{array}{r}
\max _{K_{1}, K_{2}} \int_{B}\left[\left(L\left(K_{1}\right)-L\left(K_{2}\right)\right) \max \left(\tilde{\beta}_{1}, b_{(2)}\right)+L\left(K_{2}\right) \max \left(\tilde{\beta}_{2}, b_{(3)}\right)+\pi_{1}\left(K_{1}\right)\right] \operatorname{prob}\left(b_{(1)} \geq \tilde{\beta}_{1}\right) \\
+\left[L\left(K_{2}\right)\left(\max \left(\tilde{\beta}_{2}, b_{(3)}\right)\right)+\pi_{2}\left(K_{2}\right)\right] \operatorname{prob}\left(b_{(2)} \geq \tilde{\beta}_{2}\right) g(b) d b
\end{array}
$$


Notice that $\frac{\partial \tilde{\beta_{1}}}{\partial K_{1}}<0$ and $\frac{\partial \tilde{\beta_{2}}}{\partial K_{2}}<0$. Hence, increasing the level of investments has an ambiguous effect.

\subsection{The Role of Commitment to Investment Quantities}

In the auction model and in the derivation of the optimal mechanism thus far, we have assumed that the firm commits to levels of capital investment $\left(K_{1}, K_{2}\right)$ prior to the mechanism. After the reveal of the private benefits, however, the firm could potentially modify her allocation of capital. Is it in the firm's interest to do so? Since the regions would expect such an action by the firm, they would bid accordingly. For that reason, the answer is not obvious.

In this section, we describe the optimal mechanism of the firm without commitment, where the firm chooses the amounts to invest simultaneously with the allocation and payments. To do so, we slightly modify the optimisation problem introduced earlier. Instead of only choosing a vector of probabilities $x_{i}(b)$, the firm chooses, in addition, a vector of investments $k_{i}(b)=$ $\left(k_{i 1}(b), k_{i 2}(b)\right)$. We can solve for the optimal mechanism as before.

Lemma 5. Without commitment, the firm allocates the plants to the same regions but extracts more informational rents.

Proof. See Appendix.

The plants are still allocated to the two regions who value them the most. However, the actual values of capital investment are not decided until the regions have revealed their valuations. As in the auction case, the firm differentiates the two plants; as long as $b_{(1)} \neq b_{(2)}$, $k_{1}^{*} \neq k_{2}^{*}$.

Obviously, since the firm does not commit to ex ante optimal values of investment, but chooses the amount only when observing the private benefits of the regions, the firm does better in the situation without commitment. In expected value, we can show that the optimal mechanism without pre-commitment leads, ex ante, to greater expected investment by the firm. ${ }^{12}$

Proposition 5. The firm invests, in expected value, a greater quantity of capital when she does not commit to an investment decision before the regions announce their signals than when she commits.

Proof. See Appendix.

This lemma results from the assumptions on the production function and an application of Jensen's inequality. It indicates that investment is increased, but this increase comes with larger subsidies.

\section{Welfare and Policy Implications}

The previous section shows that the firm always chooses a competitive mechanism (i.e., an auction) to allocate her plants. In addition, we saw that under some conditions, the firm may

\footnotetext{
${ }^{12}$ The actual investment quantities obviously depend on the realised values of $b$.
} 
not allocate the plants at all (because of reserve subsidies). In this section, we investigate whether these bidding wars are socially desirable. More precisely, we describe the optimal allocation mechanism from the point of view of an uninformed social planner, both with and without commitment. From these discussions, we make conclusions for public policy.

\subsection{The Social Planner Problem}

To investigate this question, we study the choice of the optimal mechanism by a social planner. Precisely, we study a social planner that observes a firm that will invest $K_{1}$ and $K_{2}$ (decided ex ante), and wants to find the optimal mechanism to allocate these two plants as observed. Would the allocations and payments be the same as in the firm's optimal mechanism? The set-up is similar to the one of Lemma 4. Assuming that the social planner is uninformed about the regions' signals ${ }^{13}$ the difference is that the objective function includes the regions' welfare and considers the social cost of public funds $(\lambda)$ :

$$
E(W)=\int_{B}\left[\sum_{i=1}^{n} E U_{i}-\lambda \sum_{i=1}^{n} s_{i}(b)+E(\Pi)\right] g(b) d b
$$

Noting that the subsidies received by the firm are paid by the regions, and so can be considered as lump-sum transfers, the social welfare corresponds to:

$$
E(W)=\pi_{1}\left(K_{1}\right)+\pi_{2}\left(K_{2}\right)+\int_{B}\left[\sum_{i=1}^{n} x_{i}(b) b_{i} L-\lambda \sum_{i=1}^{n} s_{i}(b)\right] g(b) d b
$$

Maximization of this welfare function reveals a trade-off between allocative efficiency and social cost of the subsidies. Recall that the subsidies are socially costly (due to the social cost of public funds) and that they correspond to the benefits to the regions minus the information rents they obtain. Informational rents are thus welfare-enhancing. Formally, we have:

$$
E(W)=\pi_{1}\left(K_{1}\right)+\pi_{2}\left(K_{2}\right)+\int_{B}\left[\sum_{i=1}^{n}\left[(1-\lambda) b_{i}+\lambda \frac{1-G\left(b_{i}\right)}{g\left(b_{i}\right)}\right] x_{i}(b) L\right] g(b) d b
$$

Allocating a plant to a region with private benefits $b_{i}$ :

1. generates a benefit in terms of allocative efficiency $\left(b_{i}\right)$,

2. but, as this private benefit to the region is partially repaid as subsidies to the firm, it also generates a social cost $\left(\lambda b_{i}\right)$,

3. while the informational rents to the selected region reduces the socially costly transfers $\left(\lambda \frac{1-G\left(b_{i}\right)}{g\left(b_{i}\right)}\right)$.

Excluding the informational rents, the social benefit of allocative efficiency depends upon comparing points 1 and 2, i.e., comparing $\lambda$ to 1 . For $\lambda \leq 1$, the social benefits of allocative efficiency outweights the social cost. However, informational rent mitigates this result as it represents a reduction of the socially costly subsidies. In formal terms, the virtual valuation

\footnotetext{
${ }^{13}$ If the social planner has perfect information, the problem is trivial. It allocates the plants to the regions that value them the most, with no payments
} 
function (i.e., $\left.(1-\lambda) b_{i}+\lambda \frac{1-G\left(b_{i}\right)}{g\left(b_{i}\right)}\right)$ should be increasing. Therefore, we could find a $\tilde{\lambda} \leq 1$ such that if $\lambda<\tilde{\lambda}$, the auction is socially optimal. We find the following result:

Proposition 6. For $\lambda \in[0, \tilde{\lambda}]$ with $\tilde{\lambda} \leq 1$, an uninformed social planner would use an efficient auction with no reserve subsidies in order to locate the plants. The firm chooses investment quantities $K_{1}$ and $K_{2}$, as determined in (10).

Proof. See Appendix.

Hence, the mechanism described in section 3 also implements the socially optimal mechanism. Under the conditions of Proposition 4, the incentives of the firm are aligned with social welfare. However, in contrast to the firm's optimal mechanism, the social planner does not set reserve subsidies. Indeed, such reserve subsidies can induce ex-post inefficient non-attribution decisions.

The previous discussion holds for low enough levels of $\lambda$, the social cost of public funds. Of course, if $\lambda$ is large, the cost of seeking allocative efficiency (i.e. the cost of truthful revelation of the $b_{i}$ 's) may out-weight the benefits of allocating the plants in the accurate regions. Allocating the plants by auctioning should then be ruled out, and the firm must forfeit the subsidies. In turn, the firm has no incentives to manipulate the level of investments in order to optimize the level of subsidies received. We have:

Corollary 3. From a social welfare point of view, for a high level of social cost of public funds $(\lambda>\tilde{\lambda})$, it's optimal to allocate the plants randomly. Any auction process must be ruled out and the firm chooses $K_{1}=K_{2}$.

\subsection{Discussions}

The choice of investment by the social planner relative to the firm thus depends on $\lambda$. A notable finding from our model is that while the multi-establishment nature of the bidding war distorts the firm's production allocation, and increases total subsidies, an auction process remains the socially optimal way of allocating the plants. In fact, as in the simple, single-establishment case, the condition for the social planner to choose an auction process only depends on the threshold level of the social cost of public funds $(\tilde{\lambda})$. For example, with a uniform distribution, we would find that a social planner would use an auction both for a single plant and multiple plants, as long as $\lambda<\frac{1}{2}$. We summarize this finding in the following corollary.

Corollary 4. The multi-establishment nature of the bidding war does not affect the social welfare conclusions.

A more comprehensive analysis of social welfare, however, should take into account that the social planner might put different weights on different components of the social welfare function. Formally, we should rewrite the social welfare as:

$$
E(W)=\int_{B}\left[\sum_{i=1}^{n} \alpha E(\Pi)+\gamma E\left(U_{i}\right)-\lambda \sum_{i=1}^{n} s_{i}(b)\right] g(b) d b
$$

where $\alpha$ reflects the social value of the investment to shareholders in the social planner's jurisdiction, and $\gamma$ the social value of the benefits of the region. This relatively simple re-formulation 
allows us to take into account two facts. First, the profit of the firm does not necessarily accrue to the regions in the social planner's jurisdiction (for example, a fraction might go to external shareholders). In that case, $\alpha$ should be lower. Second, the expected utility of the regions consists of both public value of the plant accruing to the region as a whole (e.g., to citizens) and private benefits enjoyed by politicians. If, empirically, we observe that most benefits go to politicians, we could argue that $\gamma \approx 0$. However, if most of the benefits come as public benefits, then $\gamma>0$.

Developing the equation as previously, we obtain the following:

$$
E(W)=\pi_{1}\left(K_{1}\right)+\pi_{2}\left(K_{2}\right)+\int_{B}\left[\sum_{i=1}^{n}\left[(\alpha-\lambda) b_{i}+(\lambda+\gamma-\alpha) \frac{1-G_{i}\left(b_{i}\right)}{g\left(b_{i}\right)}\right] x_{i}(b) L\right] g(b) d b
$$

As in the simpler case, allocating the plant to a region with private benefits $b_{i}$ generates welfare in terms of allocative efficiency, but modified by the weight placed on profits distributed to local shareholders $\left(\alpha \cdot b_{i}\right)$. It also generates a cost in terms of the social cost of public funds $\left(\lambda \cdot b_{i}\right)$. The informational rent accruing to the region $\left(\frac{1-G_{i}\left(b_{i}\right)}{g\left(b_{i}\right)}\right)$ increases social welfare, but that rent increases with $\gamma$, and decreases with $\alpha$. In other words, as the social planner puts more weight on the benefits of the regions, and less weight on the benefits accruing to shareholders, the informational rent plays a larger role in the total social welfare.

The total effect is ambiguous. One interesting case is if $\gamma=0$, i.e., most of the private benefits to the regions go to politicians. In that case, defining $\tilde{\beta}_{i}=(\alpha-\lambda) b_{i}+(\lambda+\gamma-\alpha) \frac{1-G_{i}\left(b_{i}\right)}{g\left(b_{i}\right)}$, we have $\tilde{\beta}_{i}=(\alpha-\lambda) \beta\left(b_{i}\right)$, where $\beta\left(b_{i}\right)$ is the virtual valuation as defined in the firm's optimal mechanism problem. Since $\beta\left(b_{i}\right)$ is increasing, the sign of the derivative of $\tilde{\beta}_{i}$ depends on the value of $\alpha-\lambda$. In other words, if the weight placed on the firm's profits is large enough to counter-balance the social cost of public funds $(\alpha>\lambda)$, the social planner would still use an auction. However, if $\alpha<\lambda, \tilde{\beta}_{i}$ is decreasing, thus the social planner prefers a random allocation to an auction. In turn, that would imply that the firm's use of a bidding war was socially wasteful, that the firm was over-investing, and that the social planner should impose restrictions on the use of bidding wars.

\section{Conclusion}

This paper investigates how a firm can allocate investment across multiple sites strategically to attract larger subsidies from regions who participate in a bidding war for these investments. It shows that the strategic behaviour of firms has important implications on the bidding wars for plants between regions. This distinction is important, since many bidding wars involve multiestablishment (or multi-national) firms, and that such firms receive many subsidies in short periods from many local governments.

More specifically, the paper proposes a model in which a firm wishes to build new production facilities and puts regional governments in competition against each other to decide the location of those facilities. Regional governments submit bids, in the form of tax holidays or other financial packages, and the firm invests in the winning region(s). In contrast to previous models, the firm can split her production in two establishments. This split introduces new strategic 
choices for the firm, and modifies the bidding behaviour of the regional governments.

First, we find that equilibrium subsidies will depend on the firm's choice of capital amounts to invest. In particular, when she chooses asymmetric plants, total subsidies are larger. Second, we show that this bidding behaviour affects the optimal investment allocation of the firm. More specifically, she always chooses to differentiate her establishments. Therefore, the firm departs from her profit-maximising production allocation, in order to attract larger subsidies. We then compare this result to a situation without a bidding war. We find that the effect of the bidding war is ambiguous in general, but assuming a Cobb-Douglas production function, we find that total investment increases. Notably, this result is true for any distribution of the regions' private benefits from hosting the firm. Moreover, total subsidies also increase. We also describe the firm's optimal mechanism to allocate the establishments. We find that the open ascending auction used in the model implements the optimal auction, under certain conditions.

To summarise, this paper can be interpreted as two successive additions to the usual literature on bidding wars for firms. First, instead of considering a fixed investment amount, this paper allows the firm to choose the amount of capital to invest and make available in a bidding war. This addition changes the strategy of the firm, inciting her to over-invest in comparison to a situation without a bidding war. Second, we add a multi-location component: the firm can allocate the total investment across two sites. This addition modifies the firm's behaviour further, by inciting her to differentiate the amounts of investment between the production sites. In doing so, she continues to over-invest in total.

In terms of social welfare, the paper shows that while the allocation of investment is distorted versus a situation without a bidding war, the positive effect on allocative efficiency resulting from bidding wars is preserved in a multi-plant bidding war. More specifically, the regions that value the investment the most win. Indeed, we find that a social planner would optimally choose the same allocation and payment rules as the firm, implying that the bidding war described in the model is socially optimal. However, letting the firm set reserve subsidies is not socially optimal. 


\section{References}

Adams, B. (2016). The employment impact of motor vehicle assembly plant openings. Regional Science and Urban Economics, 58:57 - 70.

Barros, P. P. and Cabral, L. (2000). Competing for foreign direct investment. Review of International Economics, 8(2):360-371.

Behrens, K. and Picard, P. M. (2008). Bidding for Horizontal Multinationals. Journal of the European Economic Association, 6(6):1244-1278.

Black, D. A. and Hoyt, W. H. (1989). Bidding for firms. The American Economic Review, 79(5):1249-1256.

Bond, E. W. and Samuelson, L. (1986). Tax Holidays as Signals. The American Economic Review, 76(4):820-826.

Buts, C., Jegers, M., and Jottier, D. (2012). The effect of subsidising firms on voting behaviour: Evidence from Flemish elections. European Journal of Government and Economics, 1(1):3043.

Cowie, C., Daripa, A., and Kapur, S. (2007). Why Packaging Matters: The Role of Unit Design in Auctions.

Davies, R. B. (2005). State tax competition for foreign direct investment: a winnable war? Journal of international economics, 67(2):498-512.

Dewatripont, M. and Seabright, P. (2006). \&quot;Wasteful\&quot; Public Spending and State Aid Control. Journal of the European Economic Association, 4(2-3):513-522.

Doyle, C. and Wijnbergen, S. (1994). Taxation of foreign multinationals: A sequential bargaining approach to tax holidays. International Tax and Public Finance, 1(3):211-225.

Edmiston, K. D. (2004). Tax uncertainty and investment: A cross-country empirical examination. Economic Inquiry, 42(3):425-440.

Ekholm, K. and Forslid, R. (2001). Trade and Location with Horizontal and Vertical Multiregion Firms. The Scandinavian Journal of Economics, 103(1):101-118.

Ferrett, B. and Wooton, I. (2010). Tax competition and the international distribution of firm ownership: an invariance result. International Tax and Public Finance, 17(5):518-531.

Ferrett, B. and Wooton, I. (2013). Fiscal Competition for FDI when Bidding is Costly. Loughborough University Discussion Papers.

Figlio, D. N. and Blonigen, B. A. (2000). The Effects of Foreign Direct Investment on Local Communities. Journal of Urban Economics, 48(2):338-363.

Fox, W. F. and Murray, M. N. (2004). Do economic effects justify the use of fiscal incentives? Southern Economic Journal, 71(1):78-92.

Furusawa, T., Hori, K., and Wooton, I. (2010). A Race beyond the Bottom: The Nature of Bidding for a Firm. CESifo Working Paper Series No 3049.

Greenstone, M., Hornbeck, R., and Moretti, E. (2010). Identifying agglomeration spillovers: Evidence from winners and losers of large plant openings. Journal of Political Economy, 118(3):536-598. 
Greenstone, M. and Moretti, E. (2003). Bidding for Industrial Plants: Does Winning a'Million Dollar Plant'Increase Welfare? NBER Working Papers.

Haaparanta, P. (1996). Competition for foreign direct investments. Journal of Public Economics, 63(1):141-153.

Hanink, D. M. (1984). A portfolio theoretic approach to multiplant location analysis. Geographical analysis, 16(2):149-161.

Head, C., Ries, J. C., and Swenson, D. L. (1999). Attracting foreign manufacturing: Investment promotion and agglomeration. Regional Science and Urban Economics, 29(2):197 - 218.

Janeba, E. (2000). Tax Competition When Governments Lack Commitment: Excess Capacity as a Countervailing Threat. The American Economic Review, 90(5):1508-1519.

Justman, M., Thisse, J. F., and van Ypersele, T. (2002). Taking the Bite out of Fiscal Competition. Journal of Urban Economics, 52(2):294-315.

Justman, M., Thisse, J. F., and van Ypersele, T. (2005). Fiscal competition and regional differentiation. Regional Science and Urban Economics, 35(6):848-861.

Keen, M. and Konrad, K. A. (2014). The Theory of International Tax Competition and Coordination. Working Paper of the Max Planck Institute for Tax Law and Public Finance No. 2012-06.

King, I., McAfee, R. P., and Welling, L. (1993). Industrial Blackmail: Dynamic Tax Competition and Public Investment. The Canadian Journal of Economics / Revue canadienne d'Economique, 26(3):590-608.

King, I. and Welling, L. (1992). Commitment, efficiency and footloose firms. Economica, $59(233)$.

Klemperer, P. (2004). Auctions: Theory and Practice. Princeton University Press.

Martin, L. (1999). Sequential Location Contests in the Presence of Agglomeration Economies. Working Paper, University of Washington, pages 33-36.

Martin, L. (2000). Bidding for firms: An asymmetric auction model of interjurisdictional competition. Technical report.

Menezes, F. M. (2003). An auction theoretical approach to fiscal wars. Social Choice and Welfare, 20(1):155-166.

Menezes, F. M. and Monteiro, P. K. (2000). Auctions with endogenous participation. Review of Economic Design, 5(1):71-89.

Myerson, R. B. (1981). Optimal Auction Design. Mathematics of operations research, 6(1):5873.

Scoones, D. and Wen, J.-F. (2001). Common and Private Values of the Firm in Tax Competition. Journal of public economic theory, 3(4):373-389.

Taylor, L. (1992). Infrastructural competition among jurisdictions. Journal of Economic Behavior \&3 Organization, 49(2):241-259.

Wheeler, D. and Mody, A. (1992). International investment location decisions: The case of u.s. firms. Journal of International Economics, 33(1-2):57-76.

Wilson, J. D. (1999). Theories of tax competition. National Tax Journal, 52(2):269-304. 


\section{A Proofs}

\section{Lemma 1}

Proof. To see why these two bids are optimal, take a region $i$ with private benefits $b_{i}$ and assume that everyone else bids according to the following strategy: continue bidding until the clock reaches my private valuation. In that case, if the clock reaches $L_{2} b_{i}$ and there are still 3 or more regions in the auction, then region $i$ has no incentive to continue bidding. Indeed, if she does, whatever the stop price, she will need to pay more than her valuation if she wins. Therefore, at price $L_{2} b_{i}$, she prefers to leave the auction. Now consider prices lower than $L_{2} b_{i}$, for example $L_{2} b_{l}$. At that clock price, region $i$ has a positive valuation and would like to win. Therefore, she has no incentive to leave the auction. Therefore, the equilibrium bid for the small establishment will be equal to

$$
s_{2}^{*}\left(K_{1}, K_{2}\right)=L\left(K_{2}\right) \cdot b_{(3)}
$$

where $b_{(3)}$ is the third-highest signal among the $n$ regions.

If the two plants are of symmetric sizes (i.e., $K_{1}=K_{2}$ ), then the two remaining regions each pay $s_{2}^{*}\left(K_{1}, K_{2}\right)$ and each receive the same investment.

However, if the two plants are asymmetric (i.e., $K_{1} \neq K_{2}$ ), we still have to determine which region receives the largest investment. Both regions know that their possibilities are now to pay $s_{2}^{*}\left(K_{1}, K_{2}\right)$ and receive the small establishment, or to pay more and receive the large establishment. The bid for the largest establishment will thus be determined by the inframarginal competition between the two remaining bidders. Since at that point, the auction becomes a simple second-price auction between two bidders, it is optimal for both regions to simply withdraw once the clock price reaches their valuation of the large plant. If they continue past that price, they either win and pay a price higher than their valuation, or they lose and pay the price for the second establishment, which was already determined.

Take the decision problem of the region with the second-highest private benefits. ${ }^{14}$ It will be indifferent between the two establishments when

$$
L\left(K_{1}\right) b_{(2)}-s_{1}^{*}\left(K_{1}, K_{2}\right)=L\left(K_{2}\right) b_{(2)}-s_{2}^{*}\left(K_{1}, K_{2}\right)
$$

\footnotetext{
${ }^{14}$ Given the monotonicity of the valuation function of the regions, for any level of private benefits, regions prefer the largest establishment to the small one.
} 
By rearranging this equation and substituting the value of $s_{2}^{*}\left(K_{2}\right)$ found in eq. (A.1), we obtain the value of the highest bid

$$
s_{1}^{*}\left(K_{1}, K_{2}\right)=\left(L\left(K_{1}\right)-L\left(K_{2}\right)\right) b_{(2)}+L\left(K_{2}\right) b_{(3)}
$$

\section{Proposition 2}

Proof. The firm does not know the private benefits of the regions in the competition, but knows that they are distributed according to $g(\cdot)$ on the interval $[\underline{b}, \bar{b}]$. Her objective function can thus be expressed as

$$
\begin{aligned}
& E(\Pi)=\int_{\underline{b}}^{\bar{b}} \int_{\underline{b}}^{b_{(2)}}\left[\left(L\left(K_{1}\right)-L\left(K_{2}\right)\right) b_{(2)}+2 L\left(K_{2}\right) b_{(3)}\right. \\
&\left.+p f\left(K_{1}, L\left(K_{1}\right)\right)-w L\left(K_{1}\right)-r K_{1}+p f\left(K_{2}, L\left(K_{2}\right)\right)-w L\left(K_{2}\right)-r K_{2}\right] . \\
& h\left(b_{(2)}, b_{(3)}, n\right) d b_{(3)} d b_{(2)}
\end{aligned}
$$

where the last part $h\left(b_{(2)}, b_{(3)}, n\right)=n(n-1)(n-2) \cdot\left[1-G\left(b_{(2)}\right)\right]\left[G\left(b_{(3)}\right)\right]^{n-3} g\left(b_{(2)}\right) g\left(b_{(3)}\right)$ is the joint distribution of $b_{(2)}$ and $b_{(3)}$, and $L\left(K_{j}\right)$ is the equilibrium amount of labour for a level of capital $K_{j}$. We obtain the following first-order conditions:

$$
\begin{aligned}
& \frac{\partial E(\Pi)}{\partial K_{1}}=L^{\prime}\left(K_{1}\right) E\left(b_{(2)}\right) \\
& +p\left(\frac{\partial f\left(K_{1}, L\left(K_{1}\right)\right)}{\partial K_{1}}+\frac{\partial f\left(K_{1}, L\left(K_{1}\right)\right)}{\partial L\left(K_{1}\right)} \cdot L^{\prime}\left(K_{1}\right)\right)-w L^{\prime}\left(K_{1}\right)-r=0 \\
& \frac{\partial E(\Pi)}{\partial K_{2}}=-L^{\prime}\left(K_{2}\right) E\left(b_{(2)}\right)+2 L^{\prime}\left(K_{2}\right) E\left(b_{(3)}\right) \\
& +p\left(\frac{\partial f\left(K_{2}, L\left(K_{2}\right)\right)}{\partial K_{2}}+\frac{\partial f\left(K_{2}, L\left(K_{2}\right)\right)}{\partial L\left(K_{2}\right)} \cdot L^{\prime}\left(K_{2}\right)\right)-w L^{\prime}\left(K_{2}\right)-r=0
\end{aligned}
$$


Since $L(K)$ represents equilibrium values, the FOCs can be simplified using the Envelope Theorem. We then obtain:

$$
\begin{aligned}
& \frac{\partial E(\Pi)}{\partial K_{1}}=L^{\prime}\left(K_{1}\right) E\left(b_{(2)}\right)+p \frac{\partial f\left(K_{1}, L\left(K_{1}\right)\right)}{\partial K_{1}}-w L^{\prime}\left(K_{1}\right)-r=0 \\
& \frac{\partial E(\Pi)}{\partial K_{2}}=-L^{\prime}\left(K_{2}\right) E\left(b_{(2)}\right)+2 L^{\prime}\left(K_{2}\right) E\left(b_{(3)}\right)+p \frac{\partial f\left(K_{2}, L\left(K_{2}\right)\right)}{\partial K_{2}}-w L^{\prime}\left(K_{2}\right)-r=0
\end{aligned}
$$

Combining the two FOCs, we see that

$$
p\left(\frac{\partial f\left(K_{2}, L\left(K_{2}\right)\right)}{\partial K_{2}}-\frac{\partial f\left(K_{1}, L\left(K_{1}\right)\right)}{\partial K_{1}}\right)=L^{\prime}\left(K_{2}\right)\left(w+E\left(b_{(2)}\right)-2 E\left(b_{(3)}\right)\right)-L^{\prime}\left(K_{1}\right)\left(w+E\left(b_{(2)}\right)\right)
$$

We want to show that $K_{1} \neq K_{2}$. Let's first assume that $E\left(b_{(2)}\right) \neq E\left(b_{(3)}\right)$ (i.e., we focus on the interesting cases where the firm expects regions to have different valuations). To prove that the firm has to optimally split in asymmetric establishments, we first assume that she does not, and show that it leads to an inconsistency. Indeed, if $K_{1}=K_{2}=K$, the previous equation reduces to

$$
0=2 L^{\prime}(K)\left(E\left(b_{(2)}\right)-E\left(b_{(3)}\right)\right)
$$

Since the regions have different expected private benefits, this equation is true only if $L^{\prime}(K)=0$. However, that derivative is always positive. Therefore, we conclude that $K_{1} \neq K_{2}$.

\section{Lemma 3}

Proof. We prove this lemma by constructing an example. Take the following cumulative distribution function: $G(b)=b^{1 / 3}$ on the interval $[0,1]$. With such a distribution, $E\left(b_{(2)}\right)=\frac{n(n-1)}{(n+2)(n+3)}$ and $E\left(b_{(3)}\right)=\frac{n(n-1)(n-2) n !}{(n+3) !}$. Consequently, $E\left(b_{(2)}\right)-2 E\left(b_{(3)}\right)>0$ if and only if:

$$
\begin{aligned}
\frac{n+1}{n-2} & >2 \\
n & <5
\end{aligned}
$$

For this distribution function, if $n<5$, we have $w+E\left(b_{(2)}\right)-2 E\left(b_{(3)}\right)>w$, and the firm has larger effective marginal labour costs in the second establishment than she would under a situation with no bidding war. Consequently, she chooses a level of $K_{2}^{*}$ lower than the nobidding-war amount $\left(K_{2}^{*}<K_{n b w}\right)$. 


\section{Proposition 3}

Proof. The first-order condition for profit maximisation in one arbitrary establishment is:

$$
p \frac{\partial f(K, L(K))}{\partial K}=L^{\prime}(K)(w-x)+r
$$

where $x$ can be zero or the adjustment on marginal labour costs arising from subsidies. Rearranging this equation, we obtain:

$$
\frac{\frac{\partial f(K, L(K))}{\partial K}-r}{L^{\prime}(K)}=\Phi(K)=(w-x)
$$

We thus have a relationship between $K$ and $x$, the adjustment on the marginal cost of labour. First, let's assume that $\frac{\partial \Phi(K)}{\partial K}<0$ and $\frac{\partial^{2} \Phi(K)}{\partial K^{2}}>0$. Under these concavity assumptions, we know that a decrease in $w-x$ of a given amount (e.g., $e$ ) increases $K$ by more than an identical increase in $w-x$ would decrease $K$. Since we also know that $\left|E\left(b_{(2)}\right)-2 E\left(b_{(3)}\right)\right|<\left|-E\left(b_{(2)}\right)\right|$, the possible increase in $K_{2}$ is always lower than the decrease in $K_{1} \cdot{ }^{15}$

Therefore, if we make the assumption that $\frac{\partial \Phi(K)}{\partial K}<0$ and $\frac{\partial^{2} \Phi(K)}{\partial K^{2}}>0$, we can conclude that the increase in $K_{1}$ due to a bidding war is always larger than the decrease in $K_{2}$. Consequently, the total amount invested is always larger in a bidding war.

When are these assumptions true? Since $r$ does not change the sign of the derivatives, we can rewrite $\Phi(K)$ as

$$
\Phi^{\prime}(K)=\frac{\frac{\partial f(K, L(K))}{\partial K}}{L^{\prime}(K)}
$$

For $\frac{\partial \Phi^{\prime}(K)}{\partial K}<0$ to be true, $f(\cdot)$ needs to be more concave ("bend more") than $L(\cdot)$ (Cargo, 1965). Assuming as usual that $f(0)=0$ and $L(0)=0$, this condition is always respected if we have an interior solution in the profit maximisation problem. For $\frac{\partial^{2} \Phi^{\prime}(K)}{\partial K^{2}}>0$ to be true, we need positive third derivatives for $f(\cdot)$ and $L(\cdot)$, a positive second derivative for $L(\cdot)$, and that

$$
\frac{\partial^{3} f(K, L(K)) / \partial K^{3}}{\partial f(K, L(K)) / \partial K}>\frac{\partial^{3} L(K) / \partial K^{3}}{\partial L(K) / \partial K}
$$

We therefore need to put conditions on the third derivatives of the production and labour demand functions.

\footnotetext{
${ }^{15}$ Or they are both decreases, in which case total investment is certainly increased
} 


\section{Corollary 1}

Proof. If $f(K, L)=K^{\alpha} L^{\beta}$, and using the function $L(K)$ as in equation (7), we find that:

$$
\frac{p\left(\frac{p \beta}{w}\right)^{\frac{\beta}{1-\beta}}\left(\frac{\alpha}{1-\beta}\right) \cdot K^{\frac{\alpha}{1-\beta}-1}-r}{\left(\frac{p \beta}{w}\right)^{\frac{1}{1-\beta}}\left(\frac{\alpha}{1-\beta}\right) K^{\frac{\alpha}{1-\beta}-1}}=w-x
$$

This equation can be expressed as (with $A>0$ and $B>0$ ):

$$
A-B \cdot K^{\frac{1-\alpha-\beta}{1-\beta}}=w-x
$$

Since $0<\frac{1-\alpha-\beta}{1-\beta}<1$, Figure 1 illustrates a stylised version of the left-hand side of Equation (A.10).

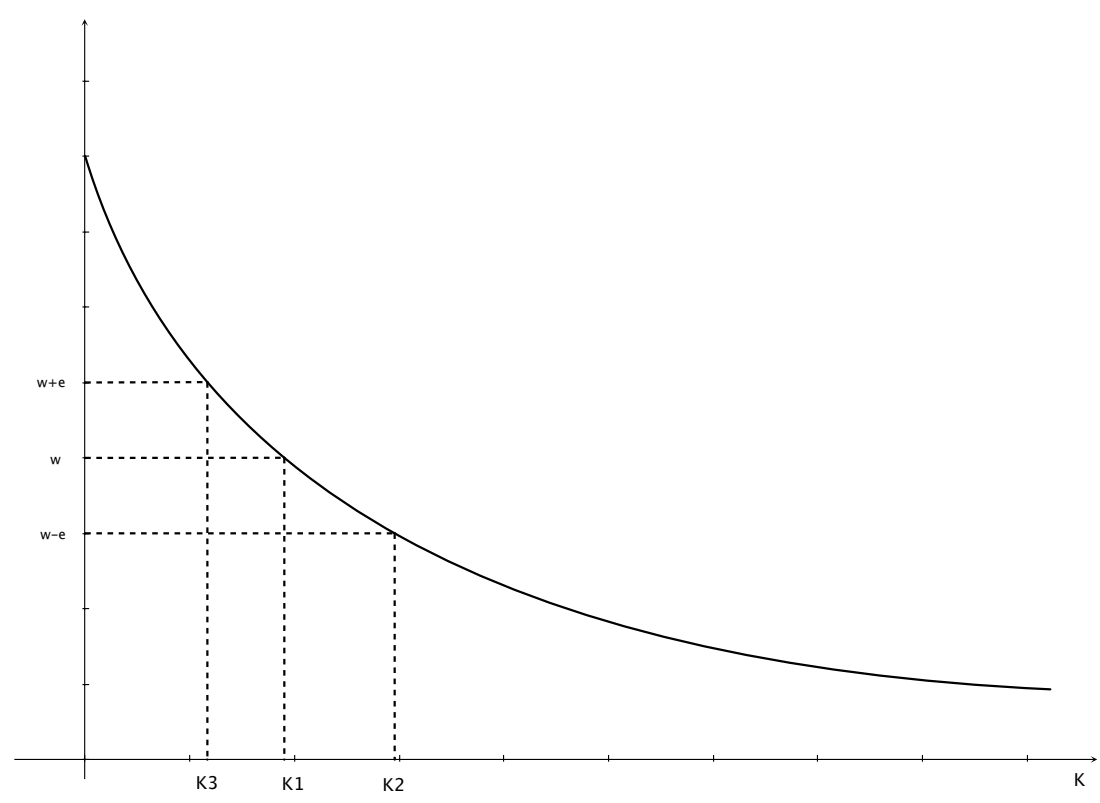

Figure 1: A stylised illustration comparing an upwards adjustment of wages to a downwards adjustment and their effects on the amount of capital invested.

In particular, since the second derivative is positive, a decrease in the right-hand side of a given amount $(e)$ increases $K$ by more than an identical increase in the right-hand side would decrease $K$. Since we know that $\left|E\left(b_{(2)}\right)-2 E\left(b_{(3)}\right)\right|<\left|-E\left(b_{(2)}\right)\right|$, the possible increase in the left-hand side (in the case of $K_{2}$ ) is always lower than the decrease in the left-hand side (in the case of $\left.K_{1}\right),{ }^{16}$ Therefore, we can conclude that the increase in $K_{1}$ due to a bidding war is always larger than the decrease in $K_{2}$. Consequently, the total amount invested is always larger

\footnotetext{
${ }^{16}$ Or they are both decreases, in which case total investment is certainly increased
} 
in a bidding war, under a Cobb-Douglas production function.

\section{Lemma 4}

Proof. Formally, the firm solves the following problem in the second stage:

$$
\begin{array}{rlr}
\max _{x(b), s(b)} & \int_{B}\left(\sum_{i=1}^{n} s_{i}(b)+\sum_{j=1}^{2}\left(\pi\left(K_{j}\right) \sum_{i=1}^{n} x_{i j}\right)\right) g(b) d b & \\
\text { s.t. } & E U_{i}\left(x_{i}, b_{i}, s_{i}\right) \geq E U_{i}\left(x_{i}, \tilde{b}_{i}, b_{-i}, s_{i}\right) & \forall i \\
& E U_{i}\left(x_{i}, b_{i}, s_{i}\right) \geq 0 \quad \forall i \forall j & I C C \\
& \sum_{i=1}^{n} x_{i j} \leq 1 \quad \forall j=1,2 & I R C \\
& x_{i j}(b) \geq 0 & F C 1 \\
& x_{i 1}(b)+x_{i 2}(b) \leq 1 & F C 2
\end{array}
$$

The Incentive Compatibility Constraint (ICC) states that it must be optimal for each region to report its true private benefits $\left(b_{i}\right)$. The Individual Rationality Constraint (IRC) states that it must be optimal for each region to participate in the mechanism. The other three constraints are feasibility constraints. FC1 states that for each plant, the allocation probabilities for all regions must sum to one or less. FC2 states that these probabilities must be non-negative. FC3 ensures that regions can, at the equilibrium, receive only one plant. Defining $\beta_{i}\left(b_{i}\right)=b_{i}-\frac{1-G\left(b_{i}\right)}{g\left(b_{i}\right)}$ as the virtual benefits of region $i$, we can express the solution to this optimisation problem as follows. First, let $x^{*}(b)$ be the solution to the following simplified optimisation problem:

$$
\begin{array}{ll}
\max _{x(b)} & \sum_{i} \int_{B}\left[\beta_{i}\left(b_{i}\right)\left(x_{i 1}(b) L\left(K_{1}\right)+x_{i 2}(b) L\left(K_{2}\right)\right)+\sum_{j=1}^{2} \pi\left(K_{j}\right) x_{i j}(b)\right] g(b) d b \\
\text { s.t. } & E U_{i}\left(x_{i}, \underline{b}, s_{i}\right)=0 \quad \forall i \\
& \left(\tilde{b}_{i}-b_{i}\right) \sum_{i=1}^{2} p_{i j}\left(x_{i}, b_{i}\right) L\left(K_{j}\right) \geq\left(\tilde{b_{i}}-b_{i}\right) \sum_{i=1}^{2} p_{i j}\left(x_{i}, \tilde{b_{i}}\right) L\left(K_{j}\right) \quad \forall b_{i}<\tilde{b}_{i} \\
& \sum_{i=1}^{n} x_{i j} \leq 1 \quad \forall j=1,2 \\
& x_{i j}(b) \geq 0 \quad \forall i, j \\
& x_{i 1}(b)+x_{i 2}(b) \leq 1 \quad \forall i
\end{array}
$$


with:

$$
\begin{aligned}
p_{i 1}\left(x_{i}, b_{i}\right) & =\int_{B_{-i}} x_{i 1}(b) g_{-i}\left(b_{-i}\right) d b_{-i} \\
p_{i 2}\left(x_{i}, b_{i}\right) & =\int_{B_{-i}} x_{i 2}(b) g_{-i}\left(b_{-i}\right) d b_{-i} \\
p_{i} & =\left(p_{i 1}, p_{i 2}\right)
\end{aligned}
$$

the marginal probabilities. Let $s_{i}^{*}(b)$ be given by:

$$
s_{i}^{*}(b)=b_{i}\left(x_{i 1}(b) L\left(K_{1}\right)+x_{i 2}(b) L\left(K_{2}\right)\right)-\int_{\underline{b}}^{b_{i}} x_{i}^{*}\left(t, b_{-i}\right) d t
$$

Then, $\left(x^{*}, s^{*}\right)$ is the optimal mechanism, with reserve subsidies corresponding to region types $b_{r 1}$ and $b_{r 2}$.

The solution to this problem in general is due to Myerson (1981). The incentive compatibility constraint (ICC) states that regional governments must have incentives to state their true private benefits. It has to be satisfied locally. Using the envelope theorem, it must be that

$$
\begin{aligned}
\frac{d E U_{i}\left(x_{i}, b_{i}, s_{i}\right)}{d b_{i}} & =\left.\frac{\partial E U_{i}\left(x_{i}, \tilde{b}_{i}, s_{i}, b_{i}\right)}{\partial b_{i}}\right|_{\tilde{b_{i}}=b_{i}} \\
& =\int_{B_{-i}}\left(x_{i 1}(b) L\left(K_{1}\right)+x_{i 2}(b) L\left(K_{2}\right)\right) g_{-i}\left(b_{-i}\right) d b_{-i}
\end{aligned}
$$

We can rewrite Equation A.11 as

$$
\frac{d E U_{i}\left(x_{i}, b_{i}, s_{i}\right)}{d b_{i}}=p_{i 1}\left(x_{i 1}, b_{i}\right) L\left(K_{1}\right)+p_{i 2}\left(x_{i 2}, b_{i}\right) L\left(K_{2}\right) \quad \forall i
$$

From Equation A.12, we can find the expected utility of a regional government such that the incentive compatibility constraint is respected:

$$
\begin{aligned}
\int_{\underline{b}}^{b_{i}} \frac{d E U_{i}\left(x_{i}, t, s_{i}\right)}{d t} d t & =\int_{\underline{b}}^{b_{i}}\left(p_{i 1}\left(x_{i}, t\right) L\left(K_{1}\right)+p_{i 2}\left(x_{i}, t\right) L\left(K_{2}\right)\right) d t \\
E U_{i}\left(x_{i}, b_{i}, s_{i}\right)-E U_{i}\left(x_{i}, \underline{b}, s_{i}\right) & =\int_{\underline{b}}^{b_{i}}\left(p_{i 1}\left(x_{i}, t\right) L\left(K_{1}\right)+p_{i 2}\left(x_{i}, t\right) L\left(K_{2}\right)\right) d t \\
E U_{i}\left(x_{i}, b_{i}, s_{i}\right) & =\int_{\underline{b}}^{b_{i}}\left(p_{i 1}\left(x_{i}, t\right) L\left(K_{1}\right)+p_{i 2}\left(x_{i}, t\right) L\left(K_{2}\right)\right) d t+E U_{i}\left(x_{i}, \underline{b}, s_{i}\right)
\end{aligned}
$$

This expected utility is thus expressed in two terms. The first term depends on the marginal 
probabilities to win one of the production sites, while the second one is the expected utility of a regional government with the lowest private benefits $(\underline{b})$.

With the incentive compatibility constraint, we can also show that $p_{i j}\left(x_{i}, b_{i}\right)$ is non-decreasing $\forall i, j$. First, we can rewrite the expected utility of a region that announces private benefits $\tilde{b}_{i}$ when he actually has private benefits $b_{i}$, and conversely, as

$$
\begin{aligned}
& E U_{i}\left(x_{i}, b_{i}, \tilde{b}_{i}, s_{i}\right)=E U_{i}\left(x_{i}, \tilde{b}_{i}, s_{i}\right)-\left(b_{i}-\tilde{b}_{i}\right)\left[L\left(K_{1}\right) p_{i 1}\left(x_{i}, \tilde{b}_{i}\right)+L\left(K_{2}\right) p_{i 2}\left(x_{i}, \tilde{b}_{i}\right)\right] \\
& E U_{i}\left(x_{i}, \tilde{b}_{i}, b_{i}, s_{i}\right)=E U_{i}\left(x_{i}, b_{i}, s_{i}\right)-\left(\tilde{b}_{i}-b_{i}\right)\left[L\left(K_{1}\right) p_{i 1}\left(x_{i}, b_{i}\right)+L\left(K_{2}\right) p_{i 2}\left(x_{i}, b_{i}\right)\right]
\end{aligned}
$$

From the incentive compatibility constraint, we thus have that

$$
\begin{aligned}
& E U_{i}\left(x_{i}, b_{i}, s_{i}\right) \geq E U_{i}\left(x_{i}, \tilde{b}_{i}, s_{i}\right)-\left(b_{i}-\tilde{b}_{i}\right)\left[L\left(K_{1}\right) p_{i 1}\left(x_{i}, \tilde{b_{i}}\right)+L\left(K_{2}\right) p_{i 2}\left(x_{i}, \tilde{b}_{i}\right)\right] \\
& E U_{i}\left(x_{i}, \tilde{b}_{i}, s_{i}\right) \geq E U_{i}\left(x_{i}, b_{i}, s_{i}\right)-\left(\tilde{b}_{i}-b_{i}\right)\left[L\left(K_{1}\right) p_{i 1}\left(x_{i}, b_{i}\right)+L\left(K_{2}\right) p_{i 2}\left(x_{i}, b_{i}\right)\right]
\end{aligned}
$$

A few manipulations show that

$$
\begin{aligned}
E U_{i}\left(x_{i}, b_{i}, s_{i}\right)-E U_{i}\left(x_{i}, \tilde{b}_{i}, s_{i}\right) & \geq\left(\tilde{b_{i}}-b_{i}\right)\left[L\left(K_{1}\right) p_{i 1}\left(x_{i}, \tilde{b}_{i}\right)+L\left(K_{2}\right) p_{i 2}\left(x_{i}, \tilde{b}_{i}\right)\right] \\
E U_{i}\left(x_{i}, b_{i}, s_{i}\right)-E U_{i}\left(x_{i}, \tilde{b}_{i}, s_{i}\right) & \leq\left(\tilde{b_{i}}-b_{i}\right)\left[L\left(K_{1}\right) p_{i 1}\left(x_{i}, b_{i}\right)+L\left(K_{2}\right) p_{i 2}\left(x_{i}, b_{i}\right)\right] \\
\left(\tilde{b_{i}}-b_{i}\right)\left[L\left(K_{1}\right) p_{i 1}\left(x_{i}, b_{i}\right)+L\left(K_{2}\right) p_{i 2}\left(x_{i}, b_{i}\right)\right] & \geq\left(\tilde{b_{i}}-b_{i}\right)\left[L\left(K_{1}\right) p_{i 1}\left(x_{i}, \tilde{b_{i}}\right)+L\left(K_{2}\right) p_{i 2}\left(x_{i}, \tilde{b}_{i}\right)\right]
\end{aligned}
$$

Therefore, if $\tilde{b_{i}}>b_{i}, L\left(K_{1}\right) p_{i 1}\left(x_{i}, b_{i}\right)+L\left(K_{2}\right) p_{i 2}\left(x_{i}, b_{i}\right)$ is non-decreasing in $b_{i}$. Defining $L=$ $\left(L\left(K_{1}\right), L\left(K_{2}\right)\right)$, we can express this equation as $L \cdot p_{i}\left(x_{i}, b_{i}\right)$. With this property, we can also simplify the individual rationality constraint to a single one:

$$
E U(x, \underline{b}, s) \geq 0
$$

The problem of the firm can now be simplified. From Equations (13) and (A.13), we know that

$$
\begin{aligned}
\int_{\underline{b}}^{b_{i}}\left[L\left(K_{1}\right) p_{i 1}\left(x_{i}, b_{i}\right)\right. & \left.+L\left(K_{2}\right) p_{i 2}\left(x_{i}, b_{i}\right)\right] d t+E U_{i}\left(x_{i}, \underline{b}, s_{i}\right) \\
& \left.=\int_{B_{-i}}\left(x_{i 1}\left(b_{i}, b_{-i}\right) L\left(K_{1}\right)+x_{i 2}\left(b_{i}, b_{-i}\right) L\left(K_{2}\right)\right) b_{i}-s_{i}\left(b_{i}, b_{-i}\right)\right) g_{-i}\left(b_{-i}\right) d b_{-i}
\end{aligned}
$$


Therefore (denoting $x_{i 1}(b) L\left(K_{1}\right)+x_{i 2}(b) L\left(K_{2}\right)$ as $\left.x_{i}(b) L\right)$,

$$
\begin{aligned}
E \Pi & =\int_{B} \sum_{i=1}^{n} s_{i}(b) g(b) d b \\
& =\sum_{i=1}^{n}\left[\int_{B} b_{i} x_{i}(b) L g(b) d b-\int_{B_{i}} \int_{\underline{b}}^{b_{i}} \int_{B_{-i}}\left(x_{i}\left(t, b_{-i}\right) L g_{-i}\left(b_{-i}\right) d b_{-i} \cdot d t \cdot g\left(b_{i}\right) d b_{i}-E U_{i}\left(x_{i}, \underline{b}, s_{i}\right)\right]\right. \\
& =\sum_{i=1}^{n}\left[\int_{B} b_{i} x_{i}(b) L g(b) d b-E U_{i}\left(x_{i}, \underline{b}, s_{i}\right)\right]-\sum_{i=1}^{n}\left[\int_{\underline{b}}^{\bar{b}} \int_{\underline{\underline{t}}}^{\bar{b}} \int_{B_{-i}}\left(x_{i}\left(t, b_{-i}\right) L g_{-i}\left(b_{-i}\right) d b_{-i} \cdot g\left(b_{i}\right) d b_{i} \cdot d t\right]\right. \\
& =\sum_{i=1}^{n}\left[\int_{B} b_{i} x_{i}(b) L g(b) d b-E U_{i}\left(x_{i}, \underline{b}, s_{i}\right)\right]-\sum_{i=1}^{n}\left[\int_{\underline{b}}^{\bar{b}} \int_{B_{-i}}\left(x_{i}\left(t, b_{-i}\right) L g_{-i}\left(b_{-i}\right) d b_{-i} \cdot(1-G(t)) \cdot d t\right]\right. \\
& =\sum_{i=1}^{n}\left[\int_{B} b_{i} x_{i}(b) L g(b) d b-E U_{i}\left(x_{i}, \underline{b}, s_{i}\right)\right]-\sum_{i=1}^{n}\left[\int_{\underline{b}}^{\bar{b}} \int_{B_{-i}}\left(x_{i}\left(b_{i}, b_{-i}\right) L g_{-i}\left(b_{-i}\right) d b_{-i} \cdot\left(1-G\left(b_{i}\right)\right) \cdot d b_{i}\right]\right. \\
& =\sum_{i=1}^{n}\left[\int_{B} b_{i} x_{i}(b) L g(b) d b-\int_{B}\left(x_{i}(b) L g(b) d b \frac{\left(1-G\left(b_{i}\right)\right)}{g_{i}\left(b_{i}\right)}\right]-\sum_{i=1}^{n}\left[E U_{i}\left(x_{i}, \underline{b}, s_{i}\right)\right]\right. \\
& =\sum_{i=1}^{n}\left[\int_{B}\left(b_{i}-\frac{\left(1-G\left(b_{i}\right)\right)}{g_{i}\left(b_{i}\right)}\right) \cdot x_{i}(b) L g(b) d b-E U_{i}\left(x_{i}, \underline{b}, s_{i}\right)\right]
\end{aligned}
$$

Define the virtual benefits of region $i$ as $\beta_{i}\left(b_{i}\right)=b_{i}-\frac{1-G\left(b_{i}\right)}{g\left(b_{i}\right)}$. We make the usual assumption that the distribution function is regular: $\beta_{i}\left(b_{i}\right)$ is increasing in $b_{i}$. We can write the firm's expected revenues as

$$
\sum_{i} \int_{B} \beta_{i}\left(b_{i}\right) x_{i 1}(b) L\left(K_{1}\right)+x_{i 2}(b) L\left(K_{2}\right) g(b) d b
$$

In doing so, we assume that at the optimum, $E U_{i}\left(x_{i}, \underline{b}, s_{i}\right)=0$. From this assumption, and Equations (13) and (A.13), we then find:

$$
\begin{aligned}
E U_{i}\left(x_{i}, b_{i}, s_{i}\right) & =\int_{\underline{b}}^{b_{i}} p_{i}\left(x_{i}, t\right) L d t \\
& =\int_{B_{-i}} \int_{\underline{b}}^{b_{i}} x_{i}\left(t, b_{-i} d t g_{-i}\left(b_{-i}\right) d b_{-i}\right. \\
& =\int_{B_{-i}}\left[b_{i}\left(x_{i 1}\left(b_{i}, b_{-i}\right) L\left(K_{1}\right)+x_{i 2}\left(b_{i}, b_{-i}\right) L\left(K_{2}\right)\right)-s_{i}\left(b_{i}, b_{-i}\right)\right] g_{-i}\left(b_{-i}\right) d b_{-i}
\end{aligned}
$$


With this equation, we can express the equilibrium payments $s_{i}^{*}(b)$ :

$$
\begin{aligned}
\int_{B}\left[b_{i}\left(x_{i 1}(b) L\left(K_{1}\right)+x_{i 2}(b) L\left(K_{2}\right)\right)-s_{i}(b)\right] g(b) d b & =\int_{B} \int_{\underline{b}}^{b_{i}} x_{i}\left(t, b_{-i}\right) d t g(b) d b \\
\int_{B} s_{i}(b) g(b) d b & =\int_{B} b_{i}\left(x_{i 1}(b) L\left(K_{1}\right)+x_{i 2}(b) L\left(K_{2}\right)\right) g(b) d b \\
& -\int_{B} \int_{\underline{b}}^{b_{i}} x_{i}\left(t, b_{-i}\right) d t g(b) d b \\
s_{i}^{*}(b) & =b_{i}\left(x_{i 1}(b) L\left(K_{1}\right)+x_{i 2}(b) L\left(K_{2}\right)\right)-\int_{\underline{b}}^{b_{i}} x_{i}^{*}\left(t, b_{-i}\right) d t
\end{aligned}
$$

Assuming $x^{*}(b)$ is the allocation function that solves the firm's problem, we can then find the optimal payment function $s_{i}^{*}(b)$ :

$$
s_{i}^{*}(b)=b_{i} \cdot\left(x_{i 1}^{*}(b) L\left(K_{1}\right)+x_{i 2}^{*}(b) L\left(K_{2}\right)\right)-\int_{\underline{b}}^{b_{i}} x_{i}^{*}\left(t, b_{-i}\right) d t
$$

The optimisation problem can therefore be expressed as follows. Let $x^{*}(b)$ be the solution to the following problem:

$$
\begin{array}{ll}
\max _{x(b)} \quad \sum_{i} \int_{B}\left[\beta_{i}\left(b_{i}\right) \cdot\left(x_{i 1}(b) L\left(K_{1}\right)+x_{i 2}(b) L\left(K_{2}\right)\right)+\sum_{j=1}^{2} \pi\left(K_{j}\right) x_{i j}(b)\right] g(b) d b \\
\text { s.t. } \quad E U_{i}\left(x_{i}, \underline{b}, s_{i}\right)=0 \quad \forall i \\
& \left(\tilde{b_{i}}-b_{i}\right) \sum_{i=1}^{2} p_{i j}\left(x_{i}, b_{i}\right) L\left(K_{j}\right) \geq\left(\tilde{b_{i}}-b_{i}\right) \sum_{i=1}^{2} p_{i j}\left(x_{i}, \tilde{b_{i}}\right) L\left(K_{j}\right) \quad \forall b_{i}<\tilde{b_{i}} \\
& \sum_{i=1}^{n} x_{i j} \leq 1 \quad \forall j=1,2 \\
& x_{i j}(b) \geq 0 \quad \forall i, j \\
& x_{i 1}(b)+x_{i 2}(b) \leq 1 \quad \forall i
\end{array}
$$

Let $s_{i}^{*}(b)$ be given by:

$$
s_{i}^{*}(b)=b_{i} \cdot\left(x_{i 1}^{*}(b) L\left(K_{1}\right)+x_{i 2}^{*}(b) L\left(K_{2}\right)\right)-\int_{\underline{b}}^{b_{i}} x_{i}^{*}\left(t, b_{-i}\right) d t
$$

Then, $\left(x^{*}, s^{*}\right)$ is the optimal mechanism. 


\section{Lemma 5}

Proof. The firm's problem becomes:

$$
\begin{array}{rlr}
\max _{x(b), k(b), s(b)} & E(\Pi)=\sum_{i=1}^{n} \int_{B}\left[x_{i 1}(b) \pi\left(k_{i 1}(b)\right)+x_{i 2}(b) \pi\left(k_{i 2}(b)\right)+s_{i}(b)\right] g(b) d b & \\
\text { s.t. } & E U_{i}\left(k_{i}, b_{i}, s_{i}\right) \geq E U_{i}\left(k_{i}, \tilde{b}_{i}, b_{-i}, s_{i}\right) & \forall i \\
& E U_{i}\left(k_{i}, b_{i}, s_{i}\right) \geq 0 \quad \forall i \forall j & I C C \\
& \sum_{i=1}^{n} x_{i j} \leq 1 \quad \forall j=1,2 & I R C \\
& x_{i j}(b) \geq 0 & F C 1 \\
& x_{i 1}(b)+x_{i 2}(b) \leq 1 & F C 2 \\
& k_{i j}(b) \geq 0 & F C 3
\end{array}
$$

By using similar manipulations on the constraints as in the constrained mechanism problem, we can transform the firm's objective function as such

$E(\Pi)=\sum_{i=1}^{n} \int_{B}\left[x_{i 1}(b) \pi\left(k_{i 1}(b)\right)+x_{i 2}(b) \pi\left(k_{i 2}(b)\right)+\beta_{i}\left(b_{i}\right)\left(x_{i 1}(b) L\left(k_{i 1}(b)\right)+x_{i 2}(b) L\left(k_{i 2}(b)\right)\right)\right] g(b) d b$

As in the previous sections, the solution for $x(b)$ is deterministic:

$$
x^{*}(b)=\left(x_{i 1}^{*}(b), x_{i 2}^{*}(b)\right)=\left\{\begin{array}{lll}
(1,0) & \text { if } & b=b_{(1)} \\
(0,1) & \text { if } & b=b_{(2)} \\
(0,0) & \text { otherwise }
\end{array}\right.
$$

What are the values of $k_{1}^{*}(b)$ and $k_{2}^{*}(b)$ ? The firm will choose these investment amounts after observing the signals. She only commits to a function $k(b)$. From the objective function, we can find the first-order condition, assuming the $b_{i}$ 's are observed, and the plants are assigned to the respective winners.

$$
\begin{aligned}
& p \frac{\partial f\left(k_{1}^{*}, L\left(k_{1}^{*}\right)\right)}{\partial k_{1}^{*}}=L^{\prime}\left(k_{1}^{*}\right)\left(w-\beta\left(b_{(1)}\right)\right)+r \\
& p \frac{\partial f\left(k_{2}^{*}, L\left(k_{2}^{*}\right)\right)}{\partial k_{2}^{*}}=L^{\prime}\left(k_{2}^{*}\right)\left(w-\beta\left(b_{(2)}\right)\right)+r
\end{aligned}
$$


These conditions define functions $k^{*}(b) .{ }^{17}$

\section{Proposition 5}

Proof. Assume for simplicity that the firm has a single establishment. The firm chooses $K$ to maximise profits. Rewrite the first-order condition of this maximisation problem as follows:

$$
p \frac{\partial f(K, L(K))}{\partial K}=L^{\prime}(K)\left(w-\beta\left(b_{(1)}\right)\right)+r
$$

We consider and compare two cases: the firm chooses investment after observing $\left\{b_{i}\right\}_{i \in[1, \ldots, n]}$, or the firm chooses investment before the signals are revealed. In the first case, the actual investment quantity will depend on revealed signals, but we can describe the expected value of that investment. First, rewrite the first-order condition:

$$
\left.\frac{\frac{\partial f\left(K^{*}(b), L\left(K^{*}(b)\right)\right)}{\partial K}-r}{L^{\prime}\left(K^{*}(b)\right)}=\Phi\left(K^{*}(b)\right)=w-\beta\left(b_{(1)}\right)\right)
$$

Therefore, we have

$$
\begin{aligned}
K^{*}(b) & \left.=\Phi^{-1}\left(w-\beta\left(b_{(1)}\right)\right)\right) \\
E\left[K^{*}(b)\right] & \left.=E\left[\Phi^{-1}\left(w-\beta\left(b_{(1)}\right)\right)\right)\right]
\end{aligned}
$$

In the second case, the firm has to commit to an investment quantity $K_{0}$ before observing the signals. Her maximisation problem is now in expected values, and the first-order condition becomes:

$$
p \frac{\partial f\left(K_{0}^{*}, L\left(K_{0}^{*}\right)\right)}{\partial K_{0}^{*}}=L^{\prime}\left(K_{0}^{*}\right)\left(w-E\left[\beta\left(b_{(1)}\right)\right]\right)+r
$$

Defining $\Phi(\cdot)$ the same way, we find that

$$
K_{0}^{*}=\Phi^{-1}\left(w-E\left[\beta\left(b_{(1)}\right)\right]\right)
$$

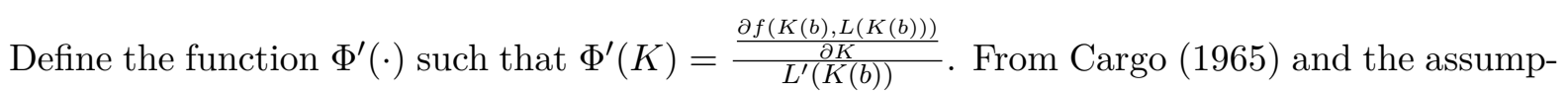
tions on $f(\cdot)$, we know that $\Phi^{\prime}(\cdot)$ is a convex decreasing function. Since $\Phi^{\prime}(\cdot)$ and $\Phi(\cdot)$ have the same derivatives, $\Phi(\cdot)$ must also be a convex decreasing function. Then, $\Phi^{-1}(\cdot)$ is also a convex

\footnotetext{
${ }^{17}$ For this optimal mechanism, a discussion on reserve subsidies is unnecessary. Indeed, reserve subsidies will be endogenously determined in the $k^{*}(b)$ functions. The firm can simply set $k^{*}(b)=0$ for some values of $b$, which is equivalent to a reserve subsidy.
} 
function. Therefore, from Jensen's inequality (as in Nagelen, 1990):

$$
\begin{aligned}
\left.E\left[\Phi^{-1}\left(w-\beta\left(b_{(1)}\right)\right)\right)\right] & \geq \Phi^{-1}\left(w-E\left[\beta\left(b_{(1)}\right)\right]\right) \\
E\left[K^{*}(b)\right] & \geq K_{0}^{*}
\end{aligned}
$$

We can make a similar argument for the second establishment.

\section{Proposition 6}

Proof. The optimisation problem of the social planner is as follows:

$$
\begin{array}{rlr}
\max _{x(b), s(b)} & E(W)=\int_{B}\left[E(\Pi)+\sum_{i=1}^{n} E U_{i}-\lambda \sum_{i=1}^{n} s_{i}(b)\right] g(b) d b & \\
\text { s.t. } & E U_{i}\left(x_{i}, b_{i}, s_{i}\right) \geq E U_{i}\left(x_{i}, \tilde{b}_{i}, b_{-i}, s_{i}\right) & \forall i \\
& E U_{i}\left(x_{i}, b_{i}, s_{i}\right) \geq 0 \quad \forall i \forall j & I C C \\
& \sum_{i=1}^{n} x_{i j} \leq 1 \quad \forall j=1,2 & \\
& x_{i j}(b) \geq 0 & F C 1 \\
& x_{i 1}(b)+x_{i 2}(b) \leq 1 & F C 2
\end{array}
$$

In this section, we assume that the firm chooses the amounts of capital to invest in a previous step, and that the mechanism is used to allocate these amounts. Therefore, $E(\Pi)=$ $\pi\left(K_{1}\right) \sum_{i=1}^{n} x_{i 1}(b)+\pi\left(K_{2}\right) \sum_{i=1}^{n} x_{i 2}(b)+\sum_{i=1}^{n} s_{i}(b)$. Since the firm has no information to reveal, she does not appear in the incentive compatibility constraints.

We can simplify the objective function as in the text:

$$
E(W)=\pi_{1}\left(K_{1}\right)+\pi_{2}\left(K_{2}\right)+\int_{B}\left[\sum_{i=1}^{n}\left[(1-\lambda) b_{i}+\lambda \frac{1-G_{i}\left(b_{i}\right)}{g\left(b_{i}\right)}\right] x_{i}(b) L\right] g(b) d b
$$

Denoting $\tilde{\beta}_{i}\left(b_{i}\right)=(1-\lambda) b_{i}+\lambda \frac{1-G_{i}\left(b_{i}\right)}{g\left(b_{i}\right)}$, we see that $\tilde{\beta}_{i}\left(b_{i}\right)$ differs from $\beta_{i}\left(b_{i}\right)$ by the addition of $\lambda$. For the social planner to use an efficient auction mechanism, we need to show that $\tilde{\beta}_{i}\left(b_{i}\right)$ is positive and increasing in $b_{i}$.

We can rearrange $\tilde{\beta}_{i}\left(b_{i}\right)$ as such:

$$
b_{i}-\lambda\left(b_{i}-\frac{1-G_{i}\left(b_{i}\right)}{g\left(b_{i}\right)}\right)=b_{i}-\lambda \beta_{i}\left(b_{i}\right)
$$


We can show that $\tilde{\beta}_{i}\left(b_{i}\right)$ is positive for any $\lambda \in[0,1]$. To do so, we need to show that $b_{i}>\lambda \beta_{i}\left(b_{i}\right)$. If $\beta_{i}\left(b_{i}\right)>0$, this is equivalent to $\lambda<\frac{b_{i}}{\beta_{i}\left(b_{i}\right)}$. Since $\beta_{i}\left(b_{i}\right)<b_{i}$, we have $\lambda \leq 1 \Longrightarrow$ $\lambda<\frac{b_{i}}{\beta_{i}\left(b_{i}\right)}$. If, instead, $\beta_{i}\left(b_{i}\right)<0$, then we need to show that $\lambda>\frac{b_{i}}{\beta_{i}\left(b_{i}\right)}$. Since here $\frac{b_{i}}{\beta_{i}\left(b_{i}\right)}<0$, we have $\lambda \geq 0 \Longrightarrow \lambda>\frac{b_{i}}{\beta_{i}\left(b_{i}\right)}$.

We can also show that $\tilde{\beta}_{i}\left(b_{i}\right)$ is increasing under some conditions on $\lambda$. We know that $\beta_{i}\left(b_{i}\right)$ is increasing in $b_{i}$ from the firm's optimal mechanism. Therefore, whether $\tilde{\beta}_{i}\left(b_{i}\right)$ is increasing depends on the magnitude of $\lambda$. If $\lambda=0$, clearly $\tilde{\beta}_{i}\left(b_{i}\right)$ is increasing in $b_{i}$. However, a larger $\lambda$ can imply a decreasing $\beta_{i}^{\prime}\left(b_{i}\right)$. The threshold $\lambda$ at which the slope changes from positive to negative will depend on the shape of the distribution function. With a uniform distribution, the threshold $\tilde{\lambda}=\frac{1}{2}$.

Finally, note that if $\lambda \leq \tilde{\lambda}$, the social planner chooses the same deterministic $x^{*}(b)$ :

$$
x^{*}(b)=\left(x_{1}^{*}(b), x_{2}^{*}(b)\right)=\left\{\begin{array}{lll}
(1,0) & \text { if } & b=b_{(1)} \\
(0,1) & \text { if } & b=b_{(2)} \\
(0,0) & \text { otherwise }
\end{array}\right.
$$

In addition, the payment rule will be the same as in the firm's optimal mechanism, but without reserve subsidies. Therefore, in the first stage of this game, the firm would choose the same allocation $\left[K_{1}, K_{2}\right]$. 